\title{
Italian consensus guidelines for chronic pancreatitis
}

\author{
Luca Frulloni ${ }^{1, *}$, Massimo Falconi ${ }^{2}$, Armando Gabbrielli ${ }^{1}$, Ezio Gaia ${ }^{3}$, Rossella Graziani ${ }^{4}$, \\ Raffaele Pezzilli ${ }^{5}$, Generoso Uomo ${ }^{6}$, Angelo Andriulli ${ }^{7}$, Gianpaolo Balzano ${ }^{8}$, Luigi Benini ${ }^{1}$, \\ Lucia Calculli $^{9}$, Donata Campra ${ }^{10}$, Gabriele Capurso ${ }^{11}$, Giulia Martina Cavestro ${ }^{12}$,
} Claudio De Angelis ${ }^{13}$, Luigi Ghezzo ${ }^{14}$, Riccardo Manfredi ${ }^{4}$, Alberto Malesci ${ }^{15}$, Alberto Mariani ${ }^{16}$, Massimiliano Mutignani ${ }^{17}$, Maurizio Ventrucci ${ }^{18}$, Giuseppe Zamboni ${ }^{4}$, Antonio Amodio ${ }^{1}$, Italo Vantini ${ }^{1}$

\author{
${ }^{I}$ Department of Medicine, University of Verona, Verona, Italy \\ ${ }^{2}$ Department of Surgery, University of Verona, Verona, Italy \\ ${ }^{3}$ Gastroenterology and Digestive Endoscopy, A.O.U. San Luigi, Turin, Italy \\ ${ }^{4}$ Department of Pathology and Radiology, University of Verona, Verona, Italy \\ ${ }^{5}$ Pancreas Unit, Department of Digestive Diseases and Internal Medicine, University of Bologna. Bologna, Italy \\ ${ }^{6}$ Department of Internal Medicine, Cardarelli Hospital, Naples, Italy \\ ${ }^{7}$ Division of Gastroenterology and Digestive Endoscopy, IRCCS “Casa Sollievo Sofferenza” Hospital, San Giovanni Rotondo, Italy \\ ${ }^{8}$ Department of Surgery, Pancreas Unit, San Raffaele Scientific Institute, Milan, Italy \\ ${ }^{9}$ Department of Radiology, Sant'Orsola-Malpighi Hospital, Bologna, Italy \\ ${ }^{10}$ U.O.A. Chirurgia Generale 7, Azienda Ospedaliera S. Giovanni Battista di Torino, Turin, Italy \\ ${ }^{11}$ Digestive and Liver Disease Unit, S. Andrea Hospital, University La Sapienza, Rome, Italy \\ ${ }^{12}$ Department of Clinical Science, University of Parma, Parma, Italy \\ ${ }^{13}$ Department of Gastro-Hepatology, Molinette Hospital, Turin, Italy \\ ${ }^{14}$ Digestive Endoscopy Unit, S. Croce e Carle Hospital, Cuneo, Italy \\ ${ }^{15}$ Division of Gastroenterology, IRCCS Istituto Clinico Humanitas, Milan, Italy \\ ${ }^{16}$ Division of Gastroenterology and Gastrointestinal Endoscopy, IRCCS San Raffaele Hospital, Milan, Italy \\ ${ }^{17}$ Digestive Endoscopy Unit, Catholic University, Rome, Italy \\ ${ }^{18}$ Department of Internal Medicine and Gastroenterology, Bentivoglio Hospital, Bologna, Italy
}

Promoter: Italian Association for the Study of the Pancreas (AISP)

AISP representatives: Claudio Bassi (President) and Gianfranco Delle Fave (past President)

Project Coordinator: Luca Frulloni

Methodology and Process Coordinator: Italo Vantini

Scientific Board: Massimo Falconi, Luca Frulloni, Armando Gabbrielli, Rossella Graziani, Raffaele Pezzilli, Italo Vantini Working party participants: Angelo Andriulli, Gianpaolo Balzano, Luigi Benini, Lucia Calculli, Donata Campra, Gabriele Capurso, Giulia Martina Cavestro, Claudio De Angelis, Massimo Falconi, Ezio Gaia, Luigi Ghezzo, Armando Gabbrielli, Rossella Graziani, Riccardo Manfredi, Alberto Malesci, Alberto Mariani, Massimiliano Mutignani, Raffaele Pezzilli, Generoso Uomo, Maurizio Ventrucci, Giuseppe Zamboni

Consensus non-voting chairman: Italo Vantini

Representative of the non-governmental organization for citizen and patient rights Cittadinanzattiva: Flavio Magarini Consensus participants: Luca Albarello (Milano), Sergio Alfieri (Roma), Antonio Amodio (Verona), Angelo Andriulli (San Giovanni Rotondo), Marcello Anti (Viterbo), Piergiorgio Arcidiacono (Milano), Luca Baiocchi (Brescia), Gianpaolo Balzano (Milano), Luigi Benini (Verona), Debora Berretti (Udine), Pietro Boraschi (Pisa), Elisabetta Buscarini (Crema), Lucia Calculli (Bologna), Antonio Carroccio (Palermo), Donata Campra (Torino), Mario Roberto Celebrano (Verona), Gabriele Capurso (Roma), Riccardo Casadei (Bologna), Giulia Martina Cavestro (Parma), Fausto Chilovi (Bolzano), Rita Conigliaro (Modena), Luigi Dall'Oglio (Roma), Claudio De Angelis (Torino), Michele De Boni (Feltre), Giovanni De Pretis (Trento), Sebastiano Di Priolo (Cagli), Pier Luigi Di Sebastiano (San Giovanni Rotondo), Giovanni Battista Doglietto (Roma), Massimo Falconi (Verona), Marco Filauro (Genova), Giuseppe Frieri (L'Aquila), Luca Frulloni (Verona), Arnaldo Fuini (Verona), Ezio Gaia (Torino), Luigi Ghezzo (Cuneo), Armando Gabbrielli (Verona), Rossella Graziani (Verona), Pietro Loriga (Cagliari), Giampiero Macarri

\footnotetext{
* Corresponding author. Luca Frulloni. Cattedra di Gastroenterologia, Policlinico GB Rossi, P.le LA Scuro, 10, 37134 Verona, Italy. Tel.: +39045 8074191; Fax: +39045 8205584. E-mail address: luca.frulloni@univr.it (L. Frulloni).
} 
(Fermo), Gianpiero Manes (Milano), Riccardo Manfredi (Verona), Alberto Malesci (Milano), Alberto Mariani (Milano), Paolo Massucco (Torino), Stefano Milani (Firenze), Massimiliano Mutignani (Roma), Claudio Pasquali (Padova), Paolo Pederzoli (Verona), Raffaele Pezzilli (Bologna), Michele Pietrangeli (Cagliari), Rodolfo Rocca (Torino), Domenico Russello (Catania), Walter Siquini (Ancona), Mario Traina (Palermo), Generoso Uomo (Napoli), Luigi Veneroni (Rimini), Maurizio Ventrucci (Bentivoglio), Maurizio Zilli (Udine), Giuseppe Zamboni (Verona).

\begin{abstract}
This paper gives practical guidelines for diagnosis and treatment of chronic pancreatitis. Statements have been elaborated by working teams of experts, by searching for and analysing the literature, and submitted to a consensus process by using a Delphi modified procedure. The statements report recommendations on clinical and nutritional approach, assessment of pancreatic function, treatment of exocrine pancreatic failure and of secondary diabetes, treatment of pain and prevention of painful relapses. Moreover, the role of endoscopy in approaching pancreatic pain, pancreatic stones, duct narrowing and dilation, and complications was considered. Recommendations for most appropriate use of various imaging techniques and of ultrasound endoscopy are reported. Finally, a group of recommendations are addressed to the surgical treatment, with definition of right indications, timing, most appropriate procedures and techniques in different clinical conditions and targets, and clinical and functional outcomes following surgery.
\end{abstract}

(C) 2010 Editrice Gastroenterologica Italiana S.r.l. Published by Elsevier Ltd. All rights reserved.

Keywords: Pancreatitis, chronic; Complications; Surgery; Radiography; Therapy; Ultrasonography; Cholangiopancreatography, endoscopic retrograde; Sphincterotomy; Diagnostic imaging; Pain; Quality of life; Steatorrhea; Pancreatic supplements

\section{Introduction}

Chronic pancreatitis is characterized by an inflammatory process of the pancreas, progressively destroying the gland, that leads to pancreatic exocrine and endocrine dysfunction. Several risk factors have been identified and/or candidated, but in a not negligible proportion of patients the disease remains idiopathic. Clinically, the early phase is characterized by pain or recurrent episodes of pancreatitis and complications, whereas in the advanced phase symptoms are related to the onset of exocrine and/or endocrine insufficiency. Chronic pancreatitis in the advanced phase is considered a risk factor for pancreatic cancer [1-3]. The therapeutic approach to chronic pancreatitis may be medical, surgical or endoscopic.

A number of recommendations for the diagnosis and treatment of chronic pancreatitis have been published in different countries [1-6], but no systematic guidelines have been published up to now.

The aim of this study was to develop guidelines for the clinical and therapeutic management of chronic pancreatitis, by using a rigorous methodology that could be used clinically by gastroenterologists, internists, radiologists, surgeons, and primary care physicians.

On the basis of imaging and molecular biology, particular forms of chronic pancreatitis have been described, e.g. autoimmune pancreatitis [7-10], paraduodenal pancreatitis [11,12], and pancreatitis associated with gene mutations $[11,13-15]$. However, nowadays there is no international agreement about their definition and/or management. Therefore, statements specifically addressed to these particular forms of the disease were not considered.

\section{Methods}

The primary aim of this document was to provide clinical guidelines for appropriate management of chronic pancreati- tis. Particular forms of chronic pancreatitis (autoimmune pancreatitis, paraduodenal pancreatitis and pancreatitis associated with gene mutations) were preliminarily excluded because available data were considered insufficient for generating specific guidelines so far.

Promoter of these guidelines was the Italian Association for the Study of the Pancreas (Associazione Italiana per lo Studio del Pancreas, AISP).

The guidelines were endorsed by the Italian Society of Gastroenterology (Società Italiana di Gastroenterologia, SIGE), the Italian Association for Gastroenterologists and Endoscopists (Associazione Italiana Gastroenterologi ed Endoscopisti Ospedalieri, AIGO), the Italian Society for Gastrointestinal Endoscopy (Società Italiana di Endoscopia Digestiva, SIED), the Italian Society of Surgery (Società Italiana di Chirurgia, SIC), and the Italian Society of Medical Radiology (Società Italiana di Radiologia Medica, SIRM).

AISP identified a Scientific Board of Experts. The Scientific Board defined methodology and targets, and acted as developer and reviewer.

The methodology to process guidelines involved five steps:

(1) The scientific board selected five main areas of interest in chronic pancreatitis: clinics, functional aspects and medical therapy, imaging, endoscopy, and surgery.

(2) For each topic, a working party was created, with a group of at least four experts each and a chairman, who selected, together with the scientific board and its chairman, clinically relevant, clear, answerable questions, focused on current practice and areas of controversy. These questions were circulated around the working parties to share relevance, improve clarity, and avoid duplication. Experts were chosen on the basis of demonstration of knowledge and competence on chronic pancreatitis and on specific topics by professional expertise and publication/research. 
Table 1a

Levels of evidence based on the Oxford Centre for Evidence-Based Medicine

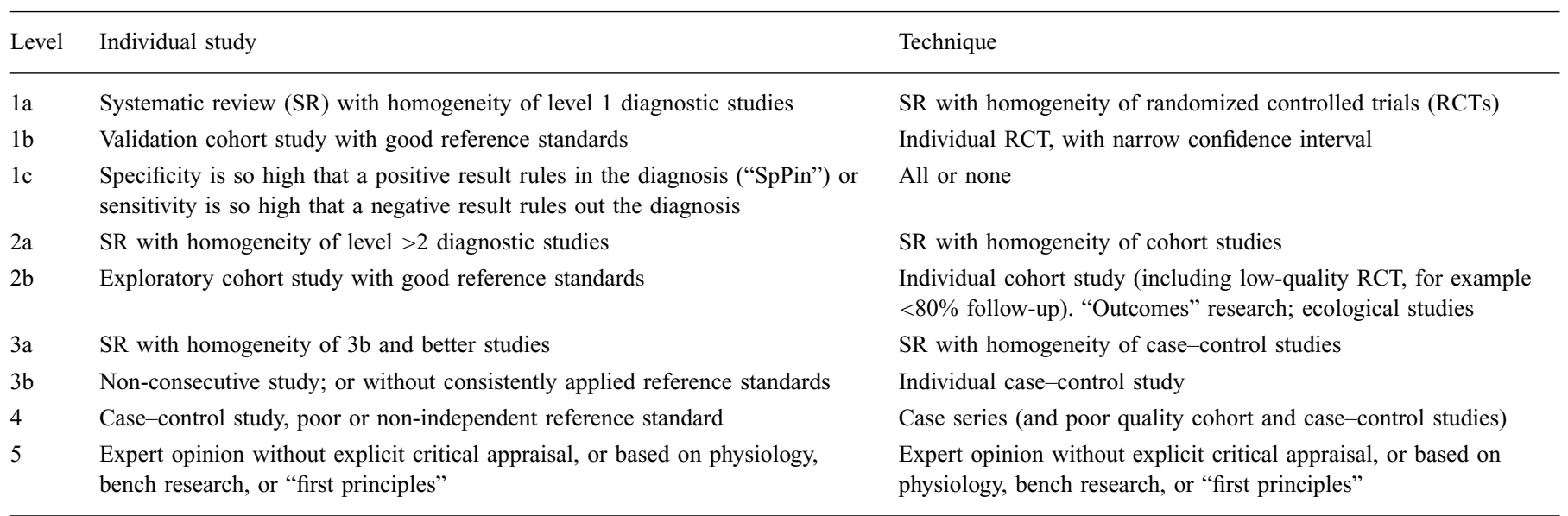

Table $1 \mathrm{~b}$

Grades of recommendation based on the Oxford Centre for Evidence-Based Medicine

\begin{tabular}{ll}
\hline Grade & Evidence base \\
\hline A & Consistent level 1 studies \\
B & Consistent level 2 or 3 studies or extrapolation from level 1 studies \\
C & Level 4 studies or extrapolation from level 2 or 3 studies \\
D & Level 5 evidence or troublingly inconsistent or inconclusive studies of any level \\
\hline
\end{tabular}

A preliminary meeting of working parties was held in Rome (April 2008) in order to share methods, aims, timelines, and the entire guideline processing.

(3) The working parties independently carried-out a systematic search for and analysis of the literature on their topics before March 2009, by using Medline/PubMed and the Cochrane data base for identifying the evidence to support the statements. Each recommendation was graded according to the Oxford Centre for EvidenceBased Medicine, based on the level of evidence (EL) (Tables 1a,b).

(4) The working parties developed initial statements within six months and attributed them a grade (strength) of recommendation $(\mathrm{RG})$ (from $\mathrm{A}$ to $\mathrm{D}$, consistent with the level of evidence) (Table 1). They were recommended to develop clear, unequivocal, sufficiently short statements that can be applied in clinical practice. A draft of provisional statements was written by the chairman of each group, and circulated within the group. A redrafted document was then prepared. Moreover, a comment for each statement was elaborated by the group and chairman, but that was not submitted to vote/formal agreement.

(5) The working parties met twice, on January $22^{\text {nd }}$ $23^{\text {rd }} 2009$ and on June $11^{\text {th }}-12^{\text {th }} 2009$, for achieving a first agreement on statements by using a simplified scale (agreement/disagreement); they voted using a modified Delphi procedure until a minimum agreement level as high as $67 \%$ was achieved for each statement. Statements were then submitted to the scientific board and chairman, who wrote an advanced version, and feedback to working parties was given for each iteration.

On November $16^{\text {th }}-17^{\text {th }} 2009$ a consensus meeting was held in Verona. The consensus group consisted of 52 participants, selected by taking into account diversity in competence and expertise in various aspects of chronic pancreatitis, and geographical distribution. The consensus group was led by a non-voting chairman (I.V.), and included experts of working parties and multi-disciplinary professionals/experts such as gastroenterologists, surgeons, radiologists, pathologists, and general practitioners. A representative of the non-governmental organization for citizen and patient rights Cittadinanzattiva took part as a non-voting observer of the meeting. Statements were submitted to the global consensus group for a first anonymous keypad voting (Delphi process) without any explanation or justification. The Delphi process allowed a change of view from a previously held position, and avoided any embarrassment of participants or influence on the individual vote. The agreement/disagreement level was scored on a six-point Likert scale as follows: A+: agree strongly; A: agree with minor reservation; A-: agree with major reservation; D-: disagree with major reservation; D: disagree with minor reservation; D+: disagree strongly. Level of agreement was expressed as percentage of each point of the scale. Immediate feedback was given to participants on a screen. They were prompted by the nonvoting chairman to discuss statements, and to suggest changes 
in the presence of controversy $(<67 \%$ agreement) or of a sum $\mathrm{A}+$ and $\mathrm{A}<80 \%$. Statements were then reviewed by a jury (the scientific board, with the exclusion of the nonvoting chairman). Two statements addressing topics already contained in other statements were included in the latter. After an open discussion driven by the non-voting chairman and focused on controversial recommendations, statements were submitted to a second anonymous keypad vote. In the review process, four statements needed further, though small changes because of insufficient clarity of wording and then were again submitted to the global consensus group for a further vote, before the final version was written. The entire consensus group work and discussion was recorded on tape. Out of 55 statements presented, 53 remained and these were approved.

The format of recommendations comprised the question, the statement, its level of evidence and strength of recommendation, and the percent agreement of the global consensus group with the final version. In the present document the statements are accompanied by qualifying comments, written by each working party and reviewed by the scientific board, by taking into account relevant comments and suggestions of the global consensus group too. Statements and their comments should be read together and not alone. In some areas the evidence level is low, reflecting the paucity of randomized trials and of good quality diagnostic studies. For some topics the expert opinion was considered, where appropriate.

\section{Statements}

\subsection{Clinics, functional aspects and medical therapy $(C)$}

\subsubsection{Clinics}

Working party: Generoso Uomo (Coordinator), Angelo Andriulli, Gabriele Capurso, Giulia Martina Cavestro, Raffaelle Pezzilli.

\subsubsection{Functional aspects and medical therapy}

Working party: Ezio Gaia (Coordinator), Luigi Benini, Alberto Malesci, Maurizio Ventrucci.

This section concerns clinical aspects, pancreatic function and medical therapy of the disease. Long-term outcome, pain, pancreatic failure, diabetes and risk of cancer were considered. The section includes clinical features, risk factors - such as alcohol and smoking - and the effect of their withdrawal on the clinical course of the disease, treatment of exocrine pancreatic failure, treatment of pain and prevention of painful relapses, and therapy of secondary diabetes. The role of pancreatic enzymes and of antioxidants in preventing pain is also discussed. The assessment of pancreatic dysfunction with clinical parameters and functional tests is considered for the identification of patients with exocrine insufficiency and for appropriate indication to enzyme-containing preparation therapy. Type, dose, timing and criteria of efficacy of pancreatic enzyme therapy are considered as well as nutritional approach.
C.1: Are there different patterns of pain in chronic pancreatitis?

Statement (EL 2b - RG B): Episodic or persistent types of pain can be present in the clinical picture of chronic pancreatitis.

Consensus Levels of Agreement:

A+ $81 \%$; A $14.1 \%$; A- $4.8 \%$; D- $0 \%$; D $0 \%$; D $+0 \%$

Abdominal pain is the dominant symptom of chronic pancreatitis. Throughout the course of the disease, $80-90 \%$ of patients complain of pain, whereas the remaining $10-20 \%$ of individuals have "painless pancreatitis" [2,12,16-18]. Pain is usually recurrent and it may be either episodic (type A: short-lived bouts of pain, lasting less than 10 days with long pain-free intervals; more frequent in idiopathic senile or late-onset chronic pancreatitis) or persistent (type B: more severe and long-lasting episodes separated by 1-2month pain-free intervals, more frequent in alcoholic chronic pancreatitis and idiopathic juvenile or early-onset chronic pancreatitis) $[2,12,16-19]$. Whether pain spontaneously burns out in late stages of uncomplicated chronic pancreatitis is still a matter of debate [5,20-26].

C.2: How can the intensity of pain be measured in chronic pancreatitis?

Statement (EL 4 - RG D): There are no specifically validated tools to score pain in chronic pancreatitis. Consensus Levels of Agreement:

A+80.9\%; A 14.9\%; A-2.1\%; D-2.1\%; D 0\%; D+ 0\%

Numerical scales ranging from "no pain" to "most severe pain", and the visual analog scale (VAS) are largely utilized in clinical trials [20]. A pain score specifically designed for chronic pancreatitis was published in 1995 [27]. This score is based on four domains that concern frequency of pain, its intensity (as indicated by VAS), need for analgesics, and disease-related inability to work; the score ranges from 0 to 100 , with higher scores indicating more severe pain. This score was successfully employed in a recent prospective controlled trial on the treatment of chronic pancreatitis [28].

C.3: Which analgesics are recommended for treating pain in chronic pancreatitis?

Statement (EL 4 - RG C): Non-steroidal anti-inflammatory drugs (NSAIDs) and narcotics are recommended for treating pain in chronic pancreatitis.

Consensus Levels of Agreement:

$\mathrm{A}+84.8 \% ; \mathrm{A} 8.7 \%$; A-2.2\%; D-2.2\%; D 2.2\%; D+ $0 \%$

Conventional NSAIDs represent the first approach to manage pain in chronic pancreatitis, but most patients with relentless pain require narcotics $[5,20,21,27,29,30]$. Tramadol should be initially preferred to morphine because of less interference with gastrointestinal functions [29]. Opioids in different formulations are similarly effective [20]. 
C.4: Does smoking withdrawal reduce pain relapses in chronic pancreatitis?

Statement (EL 4 - RG C): Smoking withdrawal is moderately effective in reducing pain relapses in chronic pancreatitis.

Consensus Levels of Agreement:

$\mathrm{A}+48.9 \%$; A 26.7\%; A- 13.3\%; D-2.2\%; D 4.4\%; D+4.4\%

It is difficult to distinguish the role of smoking from that of alcohol consumption in causation and clinical evolution of chronic pancreatitis, as cigarette smoking is often an inseparable habit in alcoholics [21-26,28,30,31]. Moreover, alcohol withdrawal is quite often not associated with smoking withdrawal. Retrospective data indicated a beneficial effect of smoking withdrawal to reduce/avoid pain and complications in chronic pancreatitis [32,33]. Experts recommend smoking withdrawal for patients with chronic pancreatitis [18].

C.5: Is alcohol withdrawal recommended for reducing pain in chronic pancreatitis?

Statement (EL 2b - RG B): Alcohol withdrawal is recommended for reducing pain in chronic pancreatitis. Consensus Levels of Agreement:

$\mathrm{A}+90.2 \%$; A 9.8\%; A- $0 \%$; D- $0 \%$; D 0\%; D+ $0 \%$

Abstinence from alcohol is an important factor influencing pain in patients with alcoholic pancreatitis. Abstainers have a slower rate of deterioration of pancreatic function and a better response to pain control by therapy than nonabstainers [18,34-40].

Moreover, exocrine pancreatic insufficiency does not progress after alcohol withdrawal [37].

C.6: Is chronic pancreatitis a risk factor for pancreatic cancer?

Statement (EL 1b - RG B): Incidence of pancreatic cancer is increased in long-lasting chronic pancreatitis.

Consensus Levels of Agreement:

A+41.3\%; A 26.1\%; A- 15.2\%; D- 4.3\%; D 0\%; D+ 0\%

The relation of chronic pancreatitis to pancreatic cancer has been addressed in several epidemiologic case-control and cohort studies. Most studies of pancreatic cancer with a case-control design [41-50] did not report the type of pancreatitis (acute or chronic). Thus, we examined the only one study in which the chronic type of pancreatitis was clearly stated [51] and having a high number of patients. In this paper a clear relationship between chronic pancreatitis and pancreatic cancer was found (OR 2.23; 95\% CI 1.433.49). Cohort studies [52-60] confirmed the relationship between chronic pancreatitis and pancreatic cancer. It should be underlined that the findings of the cohort studies must be viewed in the light of potential methodological problems: first, the recruitment of patients began from 1946 to 1973 in most studies [53-56,59,60], when it was difficult to distinguish chronic pancreatitis from pancreatic cancer; second, cancer was not confirmed histologically in all patients evaluated; third, a number of patients may have had a slower-growing cancer, such as a cystadenocarcinoma or intraductal papillary neoplasia. Finally, the possible presence of a misclassification bias is well reported in the study of Lowenfels [56]. In this study the risk of pancreatic cancer was markedly lower when data for the first two years of observation were excluded. In fact, the standardized incidence ratio was 26.3 (95\% CI 19.9-34.2) for all patients, 16.5 (95\% CI 11.123.7) for patients with two or more years of follow-up, and $14.4(95 \% \mathrm{CI} 8.5-22.8)$ for patients with five or more years of follow-up. These data have been confirmed in other reports $[51,53,55,60]$. We need further studies to reevaluate the real risk rate of pancreatic adenocarcinoma in patients with chronic pancreatitis. The prerequisite is an unequivocal diagnosis of chronic pancreatitis through more modern diagnostic tools.

C.7: Can structured questionnaires be recommended to evaluate the self-reported outcome in chronic pancreatitis?

Statement (EL 1b - RG B): Structured questionnaires are useful to evaluate the well-being of patients with chronic pancreatitis.

Consensus Levels of Agreement:

A+ 50\%; A 31.3\%; A- 12.5\%; D- 6.3\%; D 0\%; D+ 0\%

Many structured questionnaires have been utilized to assess the well-being of patients with chronic pancreatitis $[20,27,61-$ 69]. SF-12, SF-36, EORTC QLQ C-30, and GIQLI have all been proved useful. SF-12 is easier and more rapid than other tools, and gives the same information as SF-36 and EORTC QLQ C-30 [66]. However, it should be stressed that all questionnaires refer only to the month before completion of the questionnaire.

C.8: Is a change in the diet content of carbohydrates, fats and proteins indicated in chronic pancreatitis?

Statement (EL 5 - RG D): A reduction in dietary fats is recommended if steatorrhea is severe and not responding to medical treatment.

Consensus Levels of Agreement:

A+73.2\%; A 14.6\%; A-9.8\%; D- $\%$; D 0\%; D +2.4\%

There is no specific study addressing the type of macronutrient intake which may prevent late consequences of the disease. Theoretically, complex carbohydrates and dietary fibres may be useful to delay the onset of diabetes. Dietary fibres are often restricted in patients with chronic pancreatitis on the belief that they adsorb digestive enzymes and therefore interfere with their action [70,71]. This concept is however based on weak and indirect data (e.g., triolein breath tests that may be influenced by the delayed gastric emptying by fibres) [72]. No formal data are available on the need to reduce fat intake in patients with pancreatic steatorrhea, but severe steatorrhea is distressing, socially embarrassing, and may facilitate the occurrence of urinary oxalate stones. However, a reduction in fat intake is not easily accomplished, and 
may worsen the nutritional balance and vitamin levels. No interventional studies are available on the need to restrict alimentary fat in patients with pancreatic insufficiency.

C.9: Are medium-chain triglycerides (MCT) indicated in the diet of patients with chronic pancreatitis and pancreatic exocrine insufficiency?

Statement (EL 1b - RG B): MCT are not indicated in patients with chronic pancreatitis and pancreatic exocrine insufficiency.

Consensus Levels of Agreement:

$\mathrm{A}+82.6 \% ; \mathrm{A} 15.2 \% ; \mathrm{A}-2.2 \% ; \mathrm{D}-0 \% ; \mathrm{D} 0 \% ; \mathrm{D}+0 \%$

MCTs have not been shown to be effective in patients suffering from chronic pancreatitis with exocrine pancreatic insufficiency. Moreover, their poor palatability and high cost reduce the compliance of patients. Evidence exists that also MCTs require enzyme supplements for proper digestion and absorption [73]. For instance, patients with severe pancreatic insufficiency on tube feeding require pancreatic supplements for the digestion not only of polymeric formulas (which contain long-chain triglycerides), but also of elemental ones (which contain medium-chain triglycerides) [74,75].

C.10: Is vitamin supplementation recommended in patients with chronic pancreatitis?

Statement (EL 1c - RG B): Parenteral injection of lipophylic vitamins is strongly recommended in patients with severe exocrine pancreatic insufficiency.

Consensus Levels of Agreement:

$\mathrm{A}+72.9 \%$; A $14.6 \%$; A-8.3\%; D-2.1\%; D 0\%; D+2.1\%

Serum levels of lipophylic vitamins are reduced due to malabsorption caused by severe pancreatic failure [76]. This reduction has been confirmed repeatedly mainly for vitamin $\mathrm{D}$, even before the onset of overt steatorrhea [77-79]. The parenteral administration of these vitamins is therefore indicated in patients with reduced serum levels or in the presence of clinical features of malabsorption.

C.11: Are antioxidant supplements useful in chronic pancreatitis?

Statement (EL 1b - RG C): Chronic use of oral antioxidant supplements may be useful to prevent painful recurrences of chronic pancreatitis.

Consensus Levels of Agreement:

A+30.1\%; A 30.2\%; A-20.9\%; D-7\%; D 9.3\%; D+2.3\%

Only a single controlled clinical trial demonstrated that oral supplementation with antioxidants (selenium, beta-carotene, ascorbic acid, tocopherol) can be useful for the prevention of painful relapses [80]. The results of this study need to be confirmed. Previous studies were negative or inconclusive [63,8185]. Though $80 \%$ consensus rate was reached, one in five participants agreed with major reservation only. Therefore, it was considered that further studies should be carried out to confirm the above mentioned study, and the recommendation grade was set lower than the level of evidence.
C.12: Is pancreatic enzyme supplementation indicated in chronic pancreatitis?

Statement (EL 1a - RG A): Pancreatic enzyme supplementation is indicated in patients with chronic pancreatitis and exocrine pancreatic insufficiency. Consensus Levels of Agreement:

A+ 76.6\%; A 17\%; A-4.3\%; D- 2.1\%; D 0\%; D+ $0 \%$

The main clinical consequences of chronic pancreatitis are malnutrition and steatorrhea, both due to fat maldigestion [86]. Pancreatic enzyme supplementation improves fat absorption in patients with chronic pancreatitis and pancreatic exocrine insufficiency [87]. Enzyme supplementation therapy is able to normalize nutritional parameters such as liposoluble vitamins, prealbumin, and ferritin in patients without overt steatorrhea $[86,88]$. Steatorrhea occurs late in chronic pancreatitis (after a median of 10 to 12 years since the onset of the disease in about $50 \%$ of patients) [88], and it may be much more common than expected on clinical grounds only [89]. Therefore, enzyme supplementation may be considered in patients with long-lasting chronic pancreatitis [89]. Adequate treatment is relevant to avoid malnutrition-related morbidity and mortality. For instance, osteoporosis is quite common in chronic pancreatitis, due to malabsorption of vitamin D [78,79].

C.13: Is quantitative measurement of faecal fat required before prescription of pancreatic enzymes?

Statement (EL 2b - RG B): Quantitative measurement of faecal fat is not mandatory for prescribing pancreatic enzymes.

Consensus Levels of Agreement:

A+64\%; A 24\%; A-4\%; D- 2\%; D 2\%; D+0\%

Clinical diagnosis of steatorrhea (loose, greasy, foulsmelling large stools) is reached relatively late in the course of chronic pancreatitis [77]. A 72-h fecal fat collection to evaluate the coefficient of fat absorption (CFA) is the "gold standard" for diagnosis of steatorrhea; it is useful for clinical trials [88], but is not available or feasible in many instances. Pancreatic enzymes are clearly recommended to treat patients with overt steatorrhea. In chronic pancreatitis with a strong suspicion of maldigestion (weight loss, muscle wasting, osteopenia) enzyme therapy may be introduced even in absence of measurement of steatorrhea and in face of macroscopically normal stool appearance [89].

C.14: Does pancreatic enzyme supplementation improve the quality of life in patients with chronic pancreatitis?

Statement (EL 4 - RG D): Pancreatic enzyme

supplementation improves the quality of life in chronic pancreatitis.

Consensus Levels of Agreement:

A+ 48.9\%; A 29.8\%; A- 10.6\%; D- 2.1\%; D 4.3\%; D+ 4.3\%

Adequately dosed pancreatic enzyme supplementation significantly improved QoL both in patients with newly diagnosed and never treated chronic pancreatitis, and in patients receiving under-dosed pancreatic enzyme supplementation. 
In the first group, working ability, cognitive functioning, financial strain, and overall QoL scores had improved significantly after one month of enzyme supplementation therapy. Similarly, in the second group, with more severe exocrine insufficiency, QoL improved with a better control of maldigestion. Significant correlations were found in both groups between the increase in QoL and body weight or improvement in fecal fat excretion [61].

C.15: Is pancreatic enzyme supplementation recommended for reducing frequency and severity of painful relapses in chronic pancreatitis?

Statement (EL 1a - RG A): Pancreatic enzyme supplementation is not recommended for reducing frequency and severity of painful relapses in chronic pancreatitis. Consensus Levels of Agreement:

$\mathrm{A}+93.2 \% ; \mathrm{A} 4.1 \% ; \mathrm{A}-2 \% ; \mathrm{D}-0 \% ; \mathrm{D} 0 \% ; \mathrm{D}+0 \%$

A meta-analysis showed that pancreatic enzyme supplementation did not reduce pain and relapses in patients with chronic pancreatitis $[90,91]$.

C.16: Should proton pump inhibitors (PPI) be added to pancreatic enzyme supplementation in the treatment of pancreatic exocrine insufficiency in chronic pancreatitis?

Statement (EL 2a - RG C): Proton pump inhibitors should be added if steatorrhea is not controlled by pancreatic enzyme supplementation alone.

Consensus Levels of Agreement:

$\mathrm{A}+62.2 \% ; \mathrm{A} 22.2 \% ; \mathrm{A}-11.1 \% ; \mathrm{D}-0 \% ; \mathrm{D} 0 \% ; \mathrm{D}+4.4 \%$

The concomitant use of PPI is not indicated in patients with an adequate response to pancreatic enzyme supplementation therapy. However, patients with pancreatic insufficiency can have a severely impaired pancreatic bicarbonate secretion which may be insufficient to neutralize the acidity of the chyme in the duodenum $[86,92]$. This can impair the enzyme supplementation therapy, even when adequate or high enzyme doses are given. Addition of PPI is recommended in refractory steatorrhea only. There is however no clear evidence of a clinical advantage for PPI addition by using enteric-coatedmicrogranule enzyme preparations [93,94].

C.17: Which pancreatic enzyme formulation should be used and how should it be administered?

Statement (EL 1b - RG A): Pancreatic enzyme

formulations with enteric-coated $\mathrm{pH}$-sensitive minimicrospheres and high lipase content should be used.

Statement (EL 2b - RG B): The recommended dose is 25,000-40,000 units of lipase per meal. Pancreatic enzymes should be administered during or just after meals.

Consensus Levels of Agreement:

$\mathrm{A}+82.2 \% ; \mathrm{A} 17.8 \% ; \mathrm{A}-0 \% ; \mathrm{D}-0 \% ; \mathrm{D} 0 \% ; \mathrm{D}+0 \%$

The efficacy of pancreatic enzyme preparations depends on the enzyme activity released in the duodenum together with the chyme duodenal load. In pancreatic enzyme supplements, pancrelipase is formulated within $\mathrm{pH}$-sensitive enteric-coated microspheres which mix with the meal in the stomach, protect their enzyme content from gastric acidity, and empty in the duodenum with the chime, where coating rapidly disintegrates at $\mathrm{pH} \geqslant 5.5$ to release enzymes from the microspheres [86,95]. Minimicrospheres of 1.0 to $1.2 \mathrm{~mm}$ in diameter have been shown to be emptied simultaneously with the meal and are associated with a $25 \%$ higher therapeutic efficacy compared to $1.8-2.0 \mathrm{~mm}$ microspheres $[86,96]$. There is no evidence that minimicrospheres with a lower diameter increased the efficacy of enzyme supplementation on steatorrhea. Dosage should be tailored according to the severity of maldigestion and fat content of the meal. A dosage of 25,000-40,000 IU of lipase per meal is recommended [95]. A recent randomized, placebo-controlled trial in patients with chronic pancreatitis has shown that $40,000 \mathrm{IU}$ of lipase per meal and 20,000 IU per snack were able to increase fat absorption, to decrease stool frequency and to improve stool consistency [97]. A median dose of 40,000 IU of lipase per meal for one year normalized fat absorption, significantly increased body weight, normalized retinol-binding protein and prealbumin in most patients with chronic pancreatitis [88]. The efficacy of enzyme supplementation therapy seems to be higher when enzymes are administered during or just after meals [98].

C.18: How can the efficacy of pancreatic enzyme supplementation be assessed?

Statement (EL 2a - RG B): The clinical improvement of the nutritional parameters and the normalization of gastrointestinal symptoms are sufficient criteria to evaluate the efficacy of pancreatic enzymes. In non-responder patients laboratory methods for assessing fat absorption (Coefficient of Fat Absorption, ${ }^{14} \mathrm{C}$ breath test) may be used.

Consensus Levels of Agreement:

$\mathrm{A}+68.1 \% ; \mathrm{A} 29.8 \% ; \mathrm{A}-2.1 \% ; \mathrm{D}-0 \% ; \mathrm{D} 0 \% ; \mathrm{D}+0 \%$

Nutritional parameters and clinical features (body weight, stool weight and aspect) can be sufficient to assess the efficacy of enzyme supplement therapy. In patients with poor response 72-hour fecal fat collection to measure steatorrhea is suggested. Steatocrit seems to be highly correlated with fecal fat content. However, it is measured on a random specimen of stool, and the accuracy of the test depends on a highfat diet $[77,89]$. The ${ }^{13} \mathrm{C}$ mixed triglyceride breath test has been used to evaluate the efficacy of pancreatic enzyme supplementation in patients with chronic pancreatitis $[77,88]$.

C.19: Is assessment of endocrine pancreatic function recommended in chronic pancreatitis?

Statement (EL 4 - RG C): Assessment of endocrine pancreatic function is recommended by measuring fasting blood glucose levels.

Consensus Levels of Agreement:

A+ 59.2\%; A 29.5\%; A-6.8\%; D- 4.5\%; D 0\%; D+ 0\%

As there is a high frequency of diabetes in the longterm evolution of chronic pancreatitis, it is recommended to measure fasting blood glucose levels. Although there are several methods for assessing the insulin reserve in 
patients with pancreatic diabetes (basal or oral glucose tolerance test, serum/urinary insulin or C-peptide determinations, beta-cell maximal stimulation with glucagon, arginine or tolbutamide), these methods do not have any impact on decision making $[99,100]$. In a comparative study on endocrine functional tests, serum C-peptide and glucagon after arginine, but not serum insulin, were related to the severity of pancreatitis [101].

C.20: Does pancreatogenic diabetes require pharmacological and nutritional approaches differing from those of type 1 and type 2 diabetes?

Statement (EL 4 - RG C): The treatment of pancreatic diabetes does not differ from that of type 1 and type 2 diabetes.

Consensus Levels of Agreement:

A+77.3\%; A 11.4\%; A- 11.4\%; D- 0\%; D 0\%; D+ 0\%

Pancreatogenic diabetes differs from type 1 and type 2 because of higher risk for hypoglycemia and lower frequency of ketoacidosis due to impaired secretion of glucagon [57]. Complications such as macro/microangiopathy, nephropathy, neuropathy and retinopathy are as frequent as in type 1 diabetes [57]. Diet in pancreatogenic diabetes overlaps that of type 1 diabetes, even though particular care should be taken in the correction of malnutrition, vitamin and oligoelement deficiencies, and prevention of hypoglycemia with fractionated meals. With regard to insulin supply the reference glycemic target is that of type 1 diabetes, except that it has to be slightly elevated in cases of severe hypoglycemia. An educational program should be undertaken in order to avoid the onset of severe hypoglycemia; it should be focused on alcohol abolition, oriented physical activity, fractionated meals, and pancreatic enzyme adherence. There is no evidence for a role of oral hypoglycemic drugs in the treatment of pancreatogenic diabetes. The efficacy of sulphonylurea, thiazolidinedione and metformin has been reported [102]. In insulin-treated patients caution should be exercised to avoid hypoglycemia.

C.21: Is pancreatic enzyme supplementation recommended in patients with chronic pancreatitis and previous pancreatic surgical intervention?

Statement (EL 5 - RG B): Pancreatic enzyme supplementation is recommended in surgically treated patients with pancreatic exocrine insufficiency.

Consensus Levels of Agreement:

$\mathrm{A}+82.6 \%$; A 13\%; A-2.2\%; D-2.2\%; D 0\%; D+ 0\%

Surgery can impair pancreatic function. Pancreatic exocrine insufficiency (PEI) develops in patients following pancreatoduodenectomy and pylorus-preserving pancreatoduodenectomy [86,103]. PEI is found in most patients after partial pancreatic resection as well as in patients with chronic pancreatitis [86,104]. Though most studies were not specifically addressed to patients operated on for chronic pancreatitis (EL 5), participants agreed upon a RG B because in the presence of exocrine pancreatic failure enzyme supplementation is indicated in any case.

C.22: Is pancreatic function testing useful for the diagnosis of chronic pancreatitis?

Statement (EL 1c - RG B): Pancreatic function testing may be used for the diagnosis of chronic pancreatitis when imaging is not conclusive.

Consensus Levels of Agreement:

A+ 45.7\%; A 17.4\%; A- 15.2\%; D- 6.5\%; D 8.7\%; D+6.5\%

Chronic pancreatitis is an evolving process, and exocrine function is progressively impaired from a reduced functional capacity to exocrine failure in the late phase. New imaging techniques usually allow a reliable and early diagnosis of chronic pancreatitis. To detect mild or moderate exocrine pancreatic impairment, invasive tests employing a hormonal secretagogue maximally stimulating pancreatic secretion can be useful. Such tests are sensitive but poorly specific, i.e. they are not diagnostic $[105,106]$. Conversely, tubeless tests of pancreatic function can detect severe exocrine insufficiency only [107-109]. An endoscopic pancreatic test has recently been proposed as an alternative tool $[110,111]$. In selected cases, in the presence of clinical suspicion and minimal morphological changes, direct function tests can help in the diagnosis [112]. Tubeless functions tests (fecal elastase, fecal chymotrypsin) can be used in the follow-up of selected patients for identifying a progressive impairment in pancreatic function by which the chronicity of the inflammatory process can be confirmed [107,109]. Fecal elastase-1 test does not require a timed stool collection or special diet, has a high negative predictive value for pancreatic insufficiency, and a good sensitivity in patients with moderate and severe pancreatic failure [18,113]. An $80 \%$ agreement was not reached because of the lack of data comparing diagnostic power of function tests and new imaging techniques.

\subsection{Imaging (I)}

Working party: Riccardo Manfredi (Coordinator), Lucia Calculli, Claudio De Angelis, Rossella Graziani.

This section is devoted to the ability and accuracy of diagnostic imaging in answering clinical questions related to chronic pancreatitis. The role of diagnostic imaging in depicting early changes of chronic pancreatitis is analyzed. Magnetic resonance (MR) with MR cholangiopancreatography (MRCP) and dynamic MRCP following secretin administration are discussed as tools that are able to identify early changes, anatomical variants that may be associated with an increased risk of chronic pancreatitis, and to give functional information. The role of computed tomography (CT) and of ultrasonography (US) in identifying the presence and site of ductal stones and their use in acute relapses and complications is considered. The role of endoscopic ultrasound (EUS) in chronic pancreatitis and in the differential diagnosis with pancreatic cancer is reported.

For overviews of CT and MRCP see Tables 2 and 3. 
Table 2

Minimal suggested CT technique and protocol

CT should be performed nowadays with multidetector technology (MDCT), with multiplanar reconstructions.

Multiplanar reconstruction (MPR) images, according to different planes, and curvilinear reconstruction images, according to main pancreatic duct, are useful in chronic pancreatitis to assess ductal anatomy and abnormalities.

Minimum intensity protection (MinIP) and volume rendering (VR) reconstruction images may be useful in chronic pancreatitis in evaluating vascular anatomy and abnormalities.

\begin{tabular}{|c|c|c|}
\hline CT phase & Technique/Parameters & Findings \\
\hline $\begin{array}{l}\text { Un-enhanced CT }+ \text { MPR and } \\
3 \mathrm{D} \text { reconstruction }\end{array}$ & $\begin{array}{l}\text { Collimation: }<2.5 \mathrm{~mm} \text { according to the technology available. } \\
\text { Anatomical coverage: from the diaphragm to the lower pole of the kidneys }\end{array}$ & $\begin{array}{l}\text { Calcified stones } \\
\text { Hemorrhage } \\
\text { Fluid collections }\end{array}$ \\
\hline $\begin{array}{l}\text { Contrast-enhanced pancreatic phase }+ \\
\text { MPR reconstructions }\end{array}$ & $\begin{array}{l}\text { Time delay: } 35-45 \mathrm{~s} \text { from the beginning of the injection } \\
\text { Bolus tracking: } 18 \mathrm{~s} \text {, from the aortic peak using a } 90 \mathrm{HU} \text { threshold } \\
\text { Contrast agent volume }>130 \mathrm{ml} \text {; with saline flush } \\
\text { Injection rate: }>3 \mathrm{ml} / \mathrm{s} \text { : } \\
\text { Collimation: }<1 \mathrm{~mm} \\
\text { Anatomical coverage: from the diaphragm to the lower pole of the kidneys }\end{array}$ & $\begin{array}{l}\text { Focal/diffuse parenchymal fibrosis } \\
\text { Focal lesions (liquid/solid) } \\
\text { Ducts } \\
\text { Endoluminal stones } \\
\text { Vascular anatomy/abnormalities }\end{array}$ \\
\hline $\begin{array}{l}\text { Contrast-enhanced portal venous phase }+ \\
\text { MPR reconstructions }\end{array}$ & $\begin{array}{l}\text { Time delay: } 80-90 \mathrm{~s} \text { from the beginning of the injection } \\
\text { Collimation: }<2.5 \mathrm{~mm} \\
\text { Anatomical coverage: from the diaphragm to the pelvis }\end{array}$ & $\begin{array}{l}\text { Focal/diffuse parenchymal fibrosis } \\
\text { Focal lesions (liquid/solid) } \\
\text { Ducts } \\
\text { Endoluminal calculi } \\
\text { Abdominal organs } \\
\text { Ascites } \\
\text { Vascular anatomy/abnormalities }\end{array}$ \\
\hline Contrast-enhanced delayed phase + MPR & $\begin{array}{l}\text { Time delay: }>180 \mathrm{~s} \text { from the beginning of the injection } \\
\text { Collimation: }<2.5 \mathrm{~mm} \\
\text { Anatomical coverage: from the diaphragm to the pelvis }\end{array}$ & $\begin{array}{l}\text { Parenchymal fibrosis } \\
\text { Washout/retention focal lesions }\end{array}$ \\
\hline MPR Curvilinear reconstruction & & Ductal anatomy/abnormalities \\
\hline MIP-VR-3D & & Vascular anatomy/abnormalities \\
\hline
\end{tabular}

I.1: Is transabdominal US a useful diagnostic imaging technique to confirm the clinical suspicion of chronic pancreatitis?

Statement (EL 4 - RG C): Transabdominal US is useful in confirming the diagnosis of advanced chronic pancreatitis.

Consensus Levels of Agreement:

$\mathrm{A}+68.1 \%$; A 25.5\%; A-4.3\%; D-2.1\%; D 0\%; D+ 0\%

Transabdominal US is able to confirm the diagnosis of advanced chronic pancreatitis, since it identifies the thinning of the pancreatic parenchyma, the irregularity of the pancreatic margins, dilatation of the main pancreatic duct and of the side branches, and endoductal calcified stones [114116]. Transabdominal US is not able to depict early chronic pancreatitis, since it does not recognize parenchymal and ductal changes indicative of the early phase of chronic pancreatitis [114,117-127].

I.2: What is the most appropriate imaging technique for the identification of the site and the topography of pancreatic stones?

Statement (EL 3 - RG C): The most appropriate imaging technique to define the site and the topography of pancreatic stones is CT.

Consensus Levels of Agreement:

A $+59.6 \%$; A $19.2 \%$; A- $15.4 \%$; D- 5.8\%; D 0\%; D+ $0 \%$

CT without intravenous contrast media administration is the diagnostic imaging modality of choice in diagnosing pancre- atic stones typically present in advanced chronic pancreatitis. Thanks to the high spatial and contrast resolution of this tomographic technique, $\mathrm{CT}$ is able to detect ductal calcium deposits [128-130]. Furthermore it localizes pancreatic stones inside the lumen of the main pancreatic duct and/or side branches, within the pancreatic head/body/tail, or diffuse. The number and the size of the pancreatic stones are depicted without intravenous contrast agent administration. Administration of intravenous contrast agents helps in determining whether they are in the main pancreatic duct and/or in the side branches. The identification of the site of ductal stones is relevant for the endoscopic therapy. Transabdominal US is also able to diagnose pancreatic stones, especially when they present a diameter $>5 \mathrm{~mm}$ and they are localized in the pancreatic head. However, transabdominal US is limited by patient body habitus and meteorismus. Furthermore this technique shows a lower spatial and contrast resolution, therefore a negative ultrasound does not exclude the presence of stones $[129,130]$. Gadolinium-chelates enhanced MR imaging combined with MRCP is a less suitable diagnostic imaging modality for the diagnosis of pancreatic stones, since it does not depict the stones directly but only indirectly as filling defects within the pancreatic duct system. When the stones are not completely surrounded by fluid they can be missed, especially when they are less than $3 \mathrm{~mm}$ in size [131].

Conventional radiology is able to visualize pancreatic stones, especially coarse stones. However it cannot distinguish 
Table 3

Minimal suggested MR/MRCP Technique and Protocol

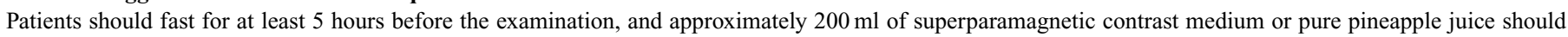
be given orally 30 minutes before the procedure to eliminate the interference of organs containing fluid on the bilio-pancreatic tree.

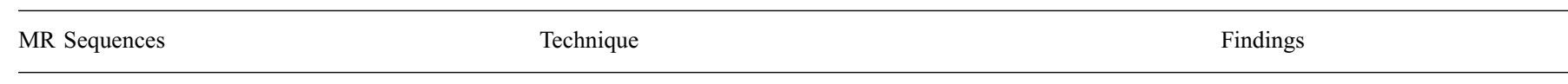

Axial chemical shift T1-weighted Gradient Echo axial images, with TE both in-phase and out-of-phase

Axial T1-weighted Gradient Echo with fat saturation

Axial and coronal T2-weighted Rapid

Acquisition with Relaxation Enhancement

(RARE) images or Half Fourier (fat-saturated)

Contrast-enhanced T1-weighted image during the Pancreatic phase during $0.1 \mathrm{mmol} / \mathrm{kg}$ body weight of gadolinium-chelates injection at $2-2.5 \mathrm{ml} / \mathrm{s}, 35-45 \mathrm{~s}$ following contrast media administration

Contrast-enhanced T1-weighted image during the portal venous phase, $75-80 \mathrm{~s}$ following contrast media administration

Contrast-enhanced T1-weighted image during the portal venous phase $>180 \mathrm{~s}$ following contrast media administration

MRCP

Dynamic MRCP during secretin administration
Dynamic study during gadolinium-chelates injection possibly obtained by means of a 3D volumetric Gradient Echo pulse sequence with fat saturation, along the axial plane
Parenchymal fibrosis

Hemorrhage

Fatty changes

Parenchymal fibrosis

Hemorrhage

Parenchymal structure

Fatty changes

Ascites

Stones

Focal lesions (solid/cystic)

Ductal anatomy/abnormalities

Fluid collections

Same as CT

Same as CT

Same as CT

2D Half Fourier RARE heavily T2-weighted pulse sequence, during breath-hold, along the most appropriate coronal/coronal oblique plane demonstrating the pancreatic duct system as well as the biliary tree, both papillae, and the duodenum

Secretin (1 clinical unit $/ \mathrm{kg}$ ) is administered before the examination and appropriate evaluation
Ductal anatomy

Endoluminal filling defects

Ductal stenosis

Dilated MPD and/or side branches

Ductal anatomy

Functional assessment

Pancreatic exocrine reserve their topography. EUS is comparable to CT in depicting site and topography of pancreatic stones, being able to visualize also very small stones $(<3 \mathrm{~mm})$. EUS is a minimally invasive imaging modality and is used as a problem solving technique [127].

I.3: What is the imaging technique of choice to diagnose early chronic pancreatitis?

Statement (EL 3a - RG B): MR imaging with MRCP, before and after secretin administration, and EUS are the most appropriate imaging techniques to diagnose parenchymal and ductal changes in early chronic pancreatitis.

Consensus Levels of Agreement:

$\mathrm{A}+71.2 \%$; A $21.2 \% ; \mathrm{A}-5.8 \% ; \mathrm{D}-0 \% ; \mathrm{D} 1.8 \% ; \mathrm{D}+0 \%$

Gadolinium-chelates enhanced MR imaging combined with MRCP has nowadays substituted diagnostic endoscopic retrograde cholangio-pancreatography (ERCP), because it is a non-invasive technique and it is able to simultaneously assess ductal and parenchymal changes typical of early chronic pancreatitis [132].

MRCP shows a lower spatial resolution compared to ERCP, however the administration of secretin during MRCP is able to overcome this limitation.

Furthermore MRCP can be acquired dynamically during intravenous secretin administration in order to non-invasively obtain morphologic and functional information [133-139].

Recently, some authors have suggested the use of diffusionweighted (DW) imaging, dynamic gadolinium-chelates enhanced MR imaging and MRCP performed following intravenous injection of secretin: the measurement of apparent diffusion coefficient (ADC) from diffusion-weighted images before and after secretin administration may aid in the diagnosis of early chronic pancreatitis [138,140142].

EUS has recently shown its ability to diagnose early chronic pancreatitis by assessing the morphological and structural changes of the pancreatic parenchyma. The meaning of these 
pancreatic morphological changes in asymptomatic patients with normal pancreatic laboratory tests is not clear [143147].

I.4: What is the imaging technique of choice to diagnose advanced chronic pancreatitis?

Statement (EL 3a - RG B): Transabdominal US, CT and MR are able to diagnose advanced chronic pancreatitis. Consensus Levels of Agreement:

A+ $70 \%$; A $20 \%$; A- $10 \%$; D- $0 \%$; D 0\%; D+ $0 \%$

Advanced chronic pancreatitis has signs that can be depicted by means of US, CT and/or MR imaging, therefore the choice should be based on the local expertise, availability, and costs. In advanced chronic pancreatitis, EUS can be used for tissue characterization and treatment planning, because of its invasiveness.

However considering medical need and availability, most likely intravenous contrast-enhanced CT is the modality that is able to assess most of the morphological signs typical of advanced chronic pancreatitis and its complications $[119,127,145,148-150]$.

Specific clinical needs can be answered by gadoliniumchelates enhanced MR imaging, with MRCP during secretin administration, to assess the pancreatic exocrine reserve [132,138,151-153].

Most papers, however, suggest integration between the different imaging modalities, in order to better answer the different clinical questions.

I.5: Is dynamic MRCP during secretin administration useful in patients with chronic pancreatitis?

Statement (EL 3a - RG B): Dynamic MRCP during secretin administration is a problem-solving technique to identify initial morphological changes of the pancreatic duct system, hydrodynamically significant strictures and to assess the pancreatic exocrine reserve.

Consensus Levels of Agreement:

A+ $57 \%$; A 36\%; A-7\%; D- $0 \%$; D 0\%; D+ $0 \%$

Gadolinium-chelates enhanced MR imaging, combined with dynamic MRCP during secretin administration, is useful in patients with chronic pancreatitis $[132,152,153]$.

In particular, in early chronic pancreatitis dynamic MRCP during secretin administration is useful in confirming the clinical suspicion; and in identifying the causes of recurrent chronic pancreatitis, by identifying initial morphological changes of the pancreatic duct system and specifically of the side branches [152].

In advanced chronic pancreatitis, dynamic MRCP during secretin administration is useful in identifying hydrodynamically significant strictures and to assess the pancreatic exocrine reserve.

However, the cost-benefit relation is still under investigation $[132,138,152,153]$.
I.6: What is the imaging technique of choice to identify pancreatic malformations in patients with chronic pancreatitis?

Statement (EL 4 - RG C): MRCP or EUS are the most accurate imaging techniques to identify pancreatic malformations in patients with chronic pancreatitis.

Consensus Levels of Agreement:

A+61\%; A 26.8\%; A-7.4\%; D- $\%$; D 2.4\%; D+2.4\%

Good-quality studies investigating the presence of pancreatic duct malformations in chronic pancreatitis are lacking. All these malformations can be observed mainly with MRCP, with or without secretin administration, and few studies have been carried out using EUS [119,154-160]. We suggest that MRCP is the imaging technique of choice to identify pancreatic malformations in patients with chronic pancreatitis, also considering its lack of invasiveness. The use of secretin administration and dynamic MRCP improves the diagnostic accuracy of the technique [161,162].

Gadolinium-chelates enhanced MR imaging combined with MRCP has nowadays substituted diagnostic ERCP, because of its non-invasiveness and its ability to depict ductal malformations.

I.7: What is the imaging technique of choice for the assessment of a patient with chronic pancreatitis and flare of the disease?

Statement (EL 4 - RG C): CT is the technique of choice in patients with chronic pancreatitis and flare of the disease.

Consensus Levels of Agreement:

$\mathrm{A}+72.2 \%$; A 3.6\%; A-9.3\%; D- 1.9\%; D 5.6\%; D+7.4\%

Intravenous contrast-enhanced $\mathrm{CT}$ is able to confirm the diagnosis, assess severity of the flare and identify complications of the disease, addressing the same issues as in acute pancreatitis [127,131,163,164].

Gadolinium-chelates enhanced MR imaging combined with MRCP is useful in assessing some complications of chronic pancreatitis and flare of the disease because of its high contrast resolution.

MR imaging/MRCP is able to identify ruptures of the main pancreatic duct, assessment of drainability of peripancreatic collections, presence of methemoglobin, and thoraco-abdominal fistulae, because of its higher contrast resolution. In particular, MRCP easily shows loss of integrity of the main pancreatic duct, with or without pancreatic fistulas. T2-weighted MR images identify solid debris, clots and methemoglobin within peripancreatic fluid collections. All of this information is useful for treatment planning [162].

EUS can also be useful in assessing the feasibility of endoscopic drainage of peripancreatic fluid collections or post-acute pseudocysts, in selected patients. 
I.8: What is the most reliable procedure in detecting malignancy in patients with chronic pancreatitis, when clinically suspected?

Statement (EL 4 - RG C): The diagnostic tool most reliable in tissue characterization is represented by EUS with fine needle aspiration (FNA).

Consensus Levels of Agreement:

A+70.8\%; A 22\%; A-4.8\%; D-2.4\%; D 0\%; D+ 0\%

The differential diagnosis between inflammatory and malignant masses and early detection of malignancy in patients with known chronic pancreatitis remains a difficult task for all diagnostic imaging techniques, even for EUS with or without FNA $[165,166]$.

\subsection{Endoscopy (E)}

Working Party: Armando Gabbrielli (Coordinator), Luigi Ghezzo, Alberto Mariani, Massimiliano Mutignani.

With the advent of modern and non-invasive imaging techniques, the role of endoscopy in chronic pancreatitis has become therapeutic. Since ductal obstruction can play a role in the pathogenesis of pain in chronic pancreatitis, endoscopic duct decompression seems to be a rational approach [5,167]. Endoscopy is also employed for the treatment of complications of the disease. Endoscopic therapy is based on different techniques and procedures, such as pancreatic sphincterotomy, extraction of pancreatic stones, pancreatic and biliary stenting, and the drainage of pseudocysts with conventional endoscopy or with endoscopic ultrasound (EUS). Extracorporeal shock wave lithotripsy (ESWL) for pancreatic stones may be combined with endoscopic procedures.

The selection of patients for endoscopic treatment of pain and prevention of painful relapses, of jaundice, of biliary and/or pancreatic strictures or stones, and of pseudocysts is discussed. The results of endoscopic therapy should be compared with those of derivative surgery, but few comparative studies are available so far [168].

E.1: Is endoscopic therapy indicated in asymptomatic patients with chronic pancreatitis and dilation of the main pancreatic duct?

Statement (EL 5 - RGD): There is no indication to endoscopically treat asymptomatic patients with dilation of the main pancreatic duct.

Consensus Levels of Agreement:

$\mathrm{A}+84.6 \%$; A 7.7\%; A-2.6\%; D-2.6\%; D 2.6\%; D+ $0 \%$

The rationale for endoscopic drainage in patients with asymptomatic main pancreatic duct dilation is to restore pancreatic juice outflow and to prevent evolution toward pancreatic exocrine and endocrine insufficiency, delaying the process of glandular atrophy. In surgical literature a limited number of studies showed an improvement of pancreatic function after pancreojejunostomy [169]. However, there are no endoscopic studies evaluating the role of endoscopic treatment on the outcome of endocrine and exocrine pancreatic function in these patients.

E.2: Is endoscopic therapy effective for treating pain associated with main pancreatic duct dilation in chronic pancreatitis?

Statement (EL 3b - RG B): Endoscopic therapy is effective in patients with pain and main pancreatic duct dilation.

Consensus Levels of Agreement:

A+77.5\%; A 20\%; A-2.5\%; D- $0 \%$; D 0\%; D+ $0 \%$

Endoscopic treatment is effective in short-term follow-up in patients suffering from obstructive-type pain $[170,171]$. According to some studies [36,65,67], endoscopic therapy was not able to modify the various physical and mental domains evaluated by both the SF-36 [36,65] and SF-12 [67] questionnaire, whereas endoscopic therapy combined with ESWL was able to significantly improve some QoL scores (pain, weight loss, fever and jaundice) and the global QoL in about $70 \%$ of patients during a short time interval (median $7 \mathrm{mo}$, range: 5-9). Endoscopic therapy can affect the long-term clinical outcome by decreasing both the hospitalization rate for pain and the intake of analgesics [172,173]. Because of the frequent coexistence of different ductal lesions in the same patient, the effectiveness of endoscopic therapy is usually the result of combined procedures, such as sphincterotomy, stricture(s) dilation, stone(s) extraction, stent(s) placement. The aim of all these endoscopic procedures is to restore drainage of the main pancreatic duct. In the presence of intraductal obstructing stone(s), endoscopic therapy may be combined with ESWL. In two randomized controlled trials, long-term results of endoscopic treatment of pain compared to derivative surgery are conflicting [36,174]. Endoscopic therapy can be successfully repeated in case of pain relapses $[175,176]$. The spontaneous burn-out of pain in the natural history of chronic pancreatitis may interfere in the assessment of efficacy of endoscopic therapy [177]. Endoscopic drainage can be proposed as a first-line treatment in patients unfit for surgery or refusing surgery and can also be useful as a "bridge to surgery" therapy $[167,174]$.

E.3: Is endoscopic therapy indicated in chronic pancreatitis with painful relapses, but without evidence of obstruction and dilation of the main pancreatic duct?

Statement (EL 5 - RG D): There is no indication to endoscopically treat patients without obstruction and dilation of the main pancreatic duct.

Consensus Levels of Agreement:

A+75\%; A 18.2\%; A-6.8\%; D- 0\%; D 0\%; D+ 0\%

In patients with frequent painful relapses, pancreatic sphincterotomy is attempted to facilitate pancreatic juice outflow. However, there is no evidence for its efficacy in treating pain in patients without duct dilation and obstruction. 
E.4: Should ESWL be combined with endoscopic therapy in patients with pain and stones in the main pancreatic duct?

Statement (EL 2c - RG B): ESWL should be combined with endoscopic therapy in the presence of large and obstructive stones of the main pancreatic duct.

Statement (EL 1b - RG A): In patients with stones in the head or in the body of the pancreas, and without strictures of the main pancreatic duct, ESWL alone is equally effective as ESWL combined with endoscopic treatment. Consensus Levels of Agreement:

$\mathrm{A}+65.2 \%$; A 23.9\%; A-8.7\%; D-0\%; D 0\%; D+2.2\%

Endoscopic stone extraction and duct decompression is limited by the size of the stones and presence of stricture [178]. ESWL overcomes the problem of the stone size by fragmenting the stones, thus facilitating endoscopic clearance of the duct. ESWL is required in $36-68 \%$ of patients and successful rates of stone clearance of the main pancreatic duct ranged from $37 \%$ to $100 \%[115,120,173,179-187]$. Use of ultrasound instead of x-rays to locate pancreatic stones is associated with a lower fragmentation rate [188,189]. Data regarding mechanical or intraductal lithotripsy technique are limited and showed it to be technically challenging, cumbersome and requiring highly specialized equipment $[190,191]$. In a randomised controlled trial, in selected patients (one or few calcifications in the pancreatic head or body with upstream dilation of main pancreatic duct) ESWL alone reduced the number of pain episodes similarly to ESWL combined with endoscopic treatment, with significantly lower cost [192].

E.5: What is the indication for unscheduled pancreatic stent removal?

Statement (EL 3b - RG B): A pancreatic stent should be removed in case of painful relapse associated with occlusion or displacement of the stent.

Consensus Levels of Agreement:

$\mathrm{A}+70.8 \%$; A $18.8 \%$; A-4.2\%; D-2.1\%; D 4.2\%; D+0\%

Insertion of a pancreatic stent is indicated in case of dominant main pancreatic duct stricture (prepapillary stricture with upstream dilation). Current strategy calls for unscheduled stent replacement when patients become symptomatic (abdominal pain) and pancreatic duct dilation is shown by abdominal ultrasound or MRCP [175,193-196]. Early removal of a pancreatic stent can be considered if it has no effect on pain.

E.6: How long should pancreatic stenting policy be pursued?

Statement (EL 3b - RG B): Pancreatic stenting should be pursued for at least 6-12 months in presence of persistent pain relief.

Consensus Levels of Agreement:

A+ 45\%; A 35\%; A- 15\%; D-2.5\%; D 2.5\%; D+ 0\%

Currently there are two strategies in pancreatic stenting: either removing the pancreatic stent after a period of
6-12 months irrespective of the resolution of the stricture of the main pancreatic duct or substitution of pancreatic stents until stricture disappearance [175,176,193-200]. Long-term pain relief was experienced by two-thirds of patients after 12 months stenting, though resolution of the stricture was observed in a minority of patients $[176,193]$. Calibration of a single distal main pancreatic duct stricture with multiple stents insertion (range 2-4 large-bore stents for 6 months) is a promising approach recently described [198]. After stent removal, stricture resolution was observed in $95 \%$ of 17 patients. After a mean of 38 months follow-up, $84 \%$ of patients remained pain-free [198].

E.7: In the presence of common bile duct stenosis and dilation, is biliary endoscopic drainage indicated in asymptomatic patients with normal liver function tests?

Statement (EL 5 - RG D): Endoscopic therapy is not indicated in presence of common bile duct stenosis and dilation in asymptomatic patients with normal liver function tests.

Consensus Levels of Agreement:

A+78.6\%; A 26.7\%; A-0\%; D-0\%; D 2.4\%; D+2.4\%

Asymptomatic common bile duct dilation in patients with normal liver function tests may be detected by imaging techniques (MRCP, CT) in patients with chronic pancreatitis [201204]. There are no predictive factors available to stratify the risk of developing cholestasis and secondary biliary cirrhosis, and to determine which patients could benefit from an endoscopic therapy. Conservative management is highly recommended in these patients [202,204].

E.8: Is endoscopic therapy indicated in patients with chronic pancreatitis and cholestasis, jaundice or cholangitis?

Statement (EL 4 - RG C): Endoscopic therapy is indicated as a temporary effective treatment of cholestasis, jaundice or cholangitis in patients with chronic pancreatitis.

Consensus Levels of Agreement:

$\mathrm{A}+81.4 \%$; A $16.3 \%$; A-2.3\%; D- $0 \%$; D $0 \%$; D $0 \%$

Plastic stent placement is effective for short-term resolution of symptomatic biliary strictures. Stent malfunctioning with clogging and septic complications are common. Morphological resolution of stenosis in long-term follow-up studies is obtained in no more than $10 \%$ of patients [205-207]. More aggressive endoscopic therapy, by placement of multiple plastic stents, can obtain stricture resolution in $44-90 \%$ of cases with a 13-48 months follow-up period after stent removal [208-210]. Although the role of self-expandable metal stents is well established for malignant obstruction, their use in benign strictures including chronic pancreatitis is less clear and controversial [211-213]. Clogging or dysfunction of these stents is reported in $10-62 \%$ of the cases after a mean follow-up of 22-50 months. As a definite treatment, stenting should be reserved for patients with serious co-morbid disease or who refuse surgery. 
E.9: Is endoscopy indicated for the treatment of pancreatic pseudocysts?

Statement (EL 4 - RG C): Endoscopic therapy is indicated in symptomatic or complicated non-hemorrhagic pancreatic pseudocysts.

Consensus Levels of Agreement:

A+71.4\%; A $19 \%$; A-4.8\%; D- 4.8\%; D 0\%; D+ $0 \%$

Most pancreatic pseudocysts are asymptomatic and resolve spontaneously. Treatment of asymptomatic and uncomplicated pseudocysts is not indicated, regardless of the size [214]. Pseudoaneurysms are relatively frequent in association with pancreatic pseudocysts. Hemorrhagic pseudocysts are an absolute contraindication for endoscopic drainage.

Although there is a lack of evidence, endoscopic drainage may be preferred to surgical treatment because it has a better risk/benefit profile, being less invasive and providing an equally effective drainage, and it is the treatment of choice in high-risk patients [215,216]. Moreover, endoscopy does not exclude or compromise subsequent surgery. Standard endoscopic treatment without EUS depends on luminal bulging [217-222]. EUS significantly improves the safety of endoscopic drainage by visualizing the cyst (it could drain cysts without bulging) and vascular structures [223-225]. Knowledge of the etiology of the pseudocyst, morphology of main pancreatic duct (presence of stricture) and its correlation with pseudocysts (communication or not) is also crucial in planning endoscopic therapy. According to the D'Egidio classification [226], in type 3 pseudocysts (associated with pancreatic ductal obstruction and chronic pancreatitis) the collection can be drained by treating the ductal obstruction and relieving ductal hypertension only. This can be achieved by therapeutic transpapillary endotherapy only. In pseudocysts due to necrotizing pancreatitis in chronic pancreatitis (type 2), the transmural drainage technique is the treatment of choice.

\subsection{Surgery: indications and options (S)}

Working Party: Massimo Falconi (Coordinator) Gianpaolo Balzano, Donata Campra, Giuseppe Zamboni.

For experts to write about the surgical treatment of chronic pancreatitis would seem relatively simple. However, to find an evidence-based approach to the matter is extremely difficult and many questions still remain on both indications and choice of operation.

The indications for treatment are usually related to the presence of pain, defined by severity, and degree of disability. However, there is as yet no universally accepted definition of significant symptomatic pain and disability, nor consensus on the interpretation of its pathogenesis. This is a considerable problem, since pain trend is of fundamental importance in validating the results of any chosen treatment. Moreover, regarding the genesis of pain, there are two main pathogenetic hypotheses. The first is based on the assumption that the pain is caused by increased intraductal and or parenchymal pressure caused by decreased drainage of pancreatic juice into the duodenum. The second, more recent theory asserts that symptoms are due to the release of neurotransmitters into the inflammatory mass, usually located in the head of the pancreas. One's belief in either theory has important therapeutic implications. Supporters of the first hypothesis believe that the palliation of pain can be obtained by improving pancreatic drainage, endoscopically or surgically; meanwhile, supporters of the second theory maintain that palliation can only be obtained by resection of as much of the diseased gland as possible. In fact, these concepts are probably complementary, and combined surgical procedures have been extensively investigated and compared. However, we are not yet in the position to distinguish which patients will benefit from which procedure.

Other, less common indications for surgery are complications which unequivocally require a surgical approach, sometimes even urgently (e.g., pseudocysts, involvement of the biliary tree and duodenum or preoperative suspicion of neoplasia, hemorrhage). Over the last few years surgical morbidity and mortality rates have become generally acceptable and long-term results, especially on pain relief, are excellent regardless of the procedure performed. In addition, in the last few years many things have changed in the nosologic framework of the disease, certain etiological factors have been discovered, and endoscopic skills have improved, adding new options to the therapeutic armamentarium. All of these facts have resulted, at least in part, in a re-evaluation of the role of surgery in the treatment of chronic pancreatitis and ultimately the choice of intervention.

The purpose of these guidelines on surgical treatment of chronic pancreatitis, although ambitious, is: (1) to highlight those data that are based on randomized clinical trials; (2) to present a rational reading of the present literature on those points which are still controversial, and (3) finally to arrive at a systematic approach to the surgical management of chronic pancreatitis based on the different clinical pictures that usually characterize the disease.

S.1: What are the indications for surgery in patients with chronic pancreatitis without extrapancreatic complications?

Statement (EL 4 - RGC): Disabling and severe pain is the main indication for surgery.

Statement (EL 4 - RG C): The other indication for surgery is suspicion of pancreatic cancer.

Consensus Levels of Agreement:

A+76\%; A 11.6\%; A- 11.6\%; D- 0\%; D 0\%; D+ 0\%

Pain is the most frequent symptom in chronic pancreatitis, though it is variable in frequency and severity [227]. Although no prospective randomized study has yet compared conservative and surgical treatment, there is evidence that surgery is effective in pain. Surgery, tailored to the presumptive pain cause, provides lasting pain relief.

Eight randomized studies aiming to compare different treatments have been performed to date [36,174,228-233]. One of them did not include pain relief among the study 
endpoints [233]. The other seven studies accounted for overall 302 surgically treated patients and documented a substantial pain relief in most patients undergoing both derivative and resective operations. Moreover, two randomized studies showed significant benefit of surgery over endoscopic treatment for pain control in chronic pancreatitis with pancreatic duct obstruction [36,174].

Suspicion of cancer: Three different settings should be considered: 1 . the association between chronic pancreatitis and pancreatic cancer $[57,60] ; 2$. the need to distinguish between central intraductal papillary mucinous neoplasms (IPMN) and chronic pancreatitis to avoid incorrect conservative management; 3 . the need to diagnose an autoimmune pancreatitis to avoid unnecessary resections. The improvement in preoperative diagnostic tools (EUS, CT, MRI, PET, histology, laboratory tests) allows the correct diagnosis in most cases of malignancy suspicion. However, if the suspicion of cancer cannot be ruled out, the patient should undergo a resective operation and not a derivative one, to obtain adequate material for histological diagnosis. The delay in the treatment of pancreatic cancer due to misdiagnosis is often fatal $[234,235]$.

S.2: What are the indications for surgery in patients with extrapancreatic complications of chronic pancreatitis?

Statement (EL 4 - RG C): Bile duct and duodenal symptomatic obstructions are indications for surgery.

Statement (EL 4 - RG C): Symptomatic pseudocysts can be treated by surgery or endoscopy.

Statement (EL 4 - RG C): Variceal bleeding due to splenic vein thrombosis should be treated by splenectomy.

Statement (EL 5 - RG D): Prophylactic splenectomy may be considered when a patient with asymptomatic gastric varices due to splenic vein thrombosis is undergoing surgery for other complications of chronic pancreatitis.

Consensus Levels of Agreement:

$\mathrm{A}+61 \%$; A 24.4\%; A-7.3\%; D- 4.9\%; D 0\%; D+2.4\%

Bile duct obstruction occurs in about $6 \%$ of patients with symptomatic chronic pancreatitis and can be effectively treated by hepatico-jejunostomy [236]. Endobiliary stents should be used for high-risk patients.

Duodenal obstruction occurs rarely (about 1\%) [236] and, when isolated, should be treated by gastro-jejunostomy. When associated with other complications of chronic pancreatitis, such as pain and/or biliary obstruction, it should be treated with resective operations, such as duodenum-preserving procedures or pylorus-preserving pancreatico-duodenectomy (PPPD).

Pseudocysts in chronic pancreatitis occur in about one third of patients [19]. Spontaneous regression is less frequent in chronic than in acute pancreatitis [237]; in the subset of alcoholic chronic pancreatitis spontaneous regression has been described in $25.7 \%$ of cases and persistence without symptoms in $23 \%$ [238]. There is neither a prospective randomized study comparing conservative and interventional treatment of pseudocysts, nor a comparison among different interventional strategies. The risk of serious complications of asymptomatic chronic pseudocysts has been rarely assessed, but it seems to be $<10 \%[214,239]$. Therefore asymptomatic pseudocysts should be treated conservatively by first instance, irrespective of size or duration. Percutaneous drainage should not be performed in chronic pseudocysts [240,241], whereas both surgical and endoscopic treatments are effective to manage symptomatic pseudocysts [242]. However, percutaneous and endoscopic treatments have sometimes been associated with a high rate of complications, raising doubts on the role of non-operative treatment as the first-line approach $[243,244]$. Surgically, pseudocysts can be treated by anastomosis with a Roux-en-Y jejunal loop or with the stomach, or by lateral pancreatico-jejunostomy alone in case of dilated duct $(>7 \mathrm{~mm}$ ) [245]. When endoscopic treatment is preferred, endoscopic ultrasound-guided drainage seems safer than conventional endoscopic drainage [223].

Splenectomy is clearly indicated in case of symptomatic splenic vein thrombosis (variceal bleeding), whereas a prophylactic role for splenectomy is controversial [246-248]. A good compromise should be to perform a concomitant prophylactic splenectomy when a patient with left-sided portal hypertension and evidence of asymptomatic gastric varices (at endoscopy or CT) is operated for other complications of chronic pancreatitis [248].

S.3: Should surgery be indicated in patients with asymptomatic chronic pancreatitis and ductal obstruction?

Statement (EL 2b - RG B): Surgical decompression of the main pancreatic duct is not mandatory, but it may be considered in patients with asymptomatic chronic pancreatitis and ductal dilation $(>7 \mathrm{~mm})$ to prevent the progression of exocrine and endocrine insufficiency. Consensus Levels of Agreement:

$\mathrm{A}+40 \%$; A $31.1 \%$; A-22.2\%; D-4.4\%; D 0\%; D+2.2\%

Although surgery is generally considered only in the late stages of chronic pancreatitis, an alternative policy supporting early operation in patients with mild disease and dilated main pancreatic duct has been proposed since 1988. In particular, the natural rate of impairment of pancreatic exocrine and endocrine function was significantly delayed by pancreaticojejunostomy as compared with a non-operated group [249]. This notion has been further addressed in a small subset of randomized patients: after a mean follow-up of 39 months, patients with mild chronic pancreatitis and associated main pancreatic duct dilation who underwent an early derivative procedure showed a diminished rate of progressive functional impairment [169].

Moreover, in patients with chronic pancreatitis with main pancreatic duct dilation $(>7 \mathrm{~mm}$ ) and an associated pseudocyst larger than $6 \mathrm{~cm}$ in diameter, surgical drainage alone has proven to be more effective than percutaneous and/or endoscopic techniques in a non-randomized study [250]. 
Evidence in favor of a positive impact of operative decompression on pancreatic dysfunction can also be extrapolated by a recent experimental randomized study comparing early versus late surgical drainage for obstructive pancreatitis, showing that an early operation leads to a better recovery of histological changes and pancreatic exocrine function [251].

According to these findings, the presence of main pancreatic duct dilation $(>7 \mathrm{~mm})$ may represent "per se" an indication for surgical decompression in asymptomatic patients. However, a randomized controlled trial comparing early surgical decompression of pancreatic duct as opposed to primary or prolonged endoscopic drainage is warranted, and major reservation accompanied the agreement for surgery in one in five participants.

S.4: When is the appropriate timing for surgery in painful chronic pancreatitis?

Statement (EL 5 - RG D): Pancreatic surgery should be performed after failure of medical treatment and to avoid narcotic addiction, and decided in a meeting of the patient with an experienced surgeon and a gastroenterologist.

Consensus Levels of Agreement:

$\mathrm{A}+58.3 \%$; A $27.1 \%$; A- $4.4 \%$; D- $4.4 \%$; D $4.4 \%$; D $2.2 \%$

Studies evaluating the natural course of pain in chronic pancreatitis have documented a variable percentage of patients (47-80\%) achieving spontaneous pain relief in advanced chronic pancreatitis (10-15 years from onset) [19,252]. However, remission is unpredictable and a percentage of patients will suffer of pain indefinitely. The strategy of waiting for spontaneous pain relief has been defined not reliable by the American Gastroenterological Association [2]. There is no pain level to define the timing of operation, but a delay in treatment may affect quality of life, increase medical and social costs [253] and cause narcotic addiction. Of note, a previous history of non-opioid substance abuse (like alcohol) was the strongest predictor of narcotic dependence in a study on chronic non-cancer pain [254].

S.5: Is surgery the treatment of choice in patients with chronic pancreatitis who develop jaundice?

Statement (EL 3a - RG B): Surgical biliary drainage is the treatment of choice in case of stricture with persistent jaundice in chronic pancreatitis.

Consensus Levels of Agreement:

A+ 55.1\%; A 24.5\%; A-8.2\%; D-6.1\%; D 4.1\%; D $2 \%$

Advanced chronic pancreatitis is frequently complicated by common bile duct strictures and jaundice. In some instances jaundice may be recurrent or persistent, with a slightly increased risk of secondary biliary cirrhosis. Management decisions are largely dictated by the duration of jaundice, morphologic appearance of stricture, associated symptoms (e.g. pain), as well as by the suspicion of an underlying malignancy. A conservative approach has been advocated in minimally symptomatic patients with transient jaundice and in the absence of substantial alterations of liver function [255]. Recurrent jaundice or clinical presentation with cholangitis are indications for endoscopic stent placement, which has been shown to be a safe and effective procedure, with a complication rate ranging from $4 \%$ to $7 \%$ [256,257]. The possibility of stent malfunctioning with clogging, dislodgement and secondary infections must be taken into account, so that a strict follow-up is warranted. Moreover, the effectiveness of endoscopic palliation has been mostly demonstrated in the short term, with long-term results being more controversial [207,209]. Although jaundice improves soon after stent insertion, complete regression of biliary strictures occurs in a small proportion of patients, especially in the presence of pancreatic calcifications. In this regard, better results seem to be achieved with multiple, simultaneous stents rather than with a single stent [209].

Surgical biliary drainage has been recommended in case of persistent jaundice (more than one month), severe clinical presentation (cholangitis, sepsis), secondary choledocolithiasis, associated pancreatic head mass and/or inability to rule out cancer [258].

There are no randomized controlled studies comparing surgical versus endoscopic biliary drainage in chronic pancreatitis. Evidence has therefore been extrapolated by several randomized studies and a recent meta-analysis evaluating the same topic in pancreatic head carcinoma. From the metaanalysis, there was no difference in relative risk for technical success (RR 1.04, 95\% CI 0.97-1.11) and therapeutic success (RR 1.00, 95\% CI 0.93-1.08) between stenting and surgery in malignant obstructive jaundice. The relative risk of all complications was significantly reduced in those receiving stents compared to surgery (RR $0.60,95 \%$ CI $0.45-0.81$ ) with a $\mathrm{p}$ value of 0.0007 . 30-day mortality showed a trend in favor of stenting (RR $0.58,95 \%$ CI $0.32-1.04$ ), but this was not statistically significant $(p=0.07)$. The relative risk of recurrent biliary obstruction prior to death/end of study was $18.9(95 \%$ CI 5.33-64.86) in favor of surgery, which was statistically significant $(\mathrm{p}<0.00001)$ (i.e. less cholangitis, clotting and gastric outlet obstruction). There were no significant differences in survival or quality of life between the two treatment groups in any of the studies.

Accordingly, in the benign setting, surgery should be the treatment of choice in case of a symptomatic biliary stricture with jaundice persisting for more than one month. The optimal procedure still remains unclear, different operations being feasible, from a biliary by-pass (choledoco- or hepaticojejunostomy) to pancreaticoduodenectomy. In case of massforming pancreatitis and/or suspicion of an underlying malignancy, partial or complete pancreatic head resection should always be carried out.

In non-operative candidates for local (e.g. portal cavernoma) or general conditions (e.g. co-morbid diseases with high operative risk), self-expanding metal mesh stents may be considered. 
S.6: Are there any morphological criteria suggesting which type of surgical intervention has to be preferred?

Statement (EL 5 - RG D): The type of surgical intervention should be decided according to three main morphological features: 1. main pancreatic duct dilation, 2. mass-forming chronic pancreatitis, 3. small pancreatic duct disease.

Consensus Levels of Agreement:

$\mathrm{A}+72.9 \%$; A $18.8 \%$; A-8.3\%; D- $0 \%$; D $0 \%$; D+ $0 \%$

No specific study can solve this question; data are taken from reviews and clinical experiences. Chronic pancreatitis has heterogeneous features that require different surgical options, and a surgical approach tailored to morphological criteria is suggested.

Traditionally three morphological patterns may be distinguished: (1) chronic pancreatitis with main pancreatic duct dilation ( $\geqslant 7 \mathrm{~mm}$; large-duct disease); (2) chronic massforming pancreatitis (including cystic dystrophy of the duodenal wall, i.e. groove pancreatitis); (3) chronic pancreatitis with small/normal pancreatic duct ( $<7 \mathrm{~mm}$; small-duct disease). Accordingly, the different operations traditionally proposed are: drainage operation for large-duct disease, resection for mass-forming chronic pancreatitis or for small-duct disease (pancreatico-duodenectomy; PD) $[2,259,260]$.

However, each traditional technique has a percentage of long-term failure in pain relief [success rate: PD 66-89\%, lateral pancreatico-jejunostomy (LPJ) 6-84\%, distal pancreatectomy (DP) 57-81\%] [261], possibly reflecting an incorrect choice of operation based on morphological criteria.

Moreover, the morphological criteria, though being valid principles, are less important in mixed operations [local resection-lateral pancreatico-jejunostomy (LR-LPJ), duodenopreserving head resection (DPHR), Berne, V-shaped operation] that include resection and drainage at the same time and, for this reason, are not so dependent on morphology.

S.7: When should pancreatic drainage surgery be chosen? Statement (EL 5 - RG D): Drainage surgery should be chosen in case of dilation of the main pancreatic duct $(\geqslant 7 \mathrm{~mm})$, after having ruled out malignancy.

Consensus Levels of Agreement:

A+62\%; A $18 \%$; A- 12\%; D- 2\%; D 4\%; D+2\%

Data were inferred from series dated back to 19801990. Surgical drainage seems to be the first treatment required in patients with main pancreatic duct dilated to preserve pancreatic function [262]. Delcore proposed drainage operation in small-duct disease [263], but no benefit was proven [264]. The rationale of drainage operation is the hypothesis that high pressure in the duct system and the surrounding pancreatic parenchyma cause dilation of the pancreatic duct and pain $[265,266]$.

Drainage operation consists in a complete longitudinal opening of the pancreatic duct and a side-to-side pancreaticojejunostomy without resection of the pancreatic tail as proposed by Partington and Rochelle [267]. The surgical drainage of the pancreatic duct has been improved between 1954 and 1960. In 1954 Zollinger [268] and Du Val [269] first proposed an internal retrograde drainage of the pancreatic duct by means of a caudal pancreatico-jejunostomy with resection of the pancreatic tail and an end-to-end pancreaticojejunostomy. In 1958 Puestow and Gillesby [270] improved the retrograde drainage of the caudal pancreatico-jejunostomy carrying out a longitudinal opening of the distal pancreatic duct (after tail resection) and a side-to-side pancreaticojejunostomy. Finally, in 1960 Partington and Rochelle [267] modified Puestow's procedure to obtain a complete drainage of the pancreatic duct by LPJ.

Mortality rates of drainage operation are very low $(0-5 \%)$ and short-term pain relief is obtained in about $80 \%$ of patients [256].

S.8: What is the drainage surgery of choice in chronic pancreatitis?

Statement (EL 4 - RG C): The lateral pancreaticojejunostomy (LPJ) procedure proposed by Partington and Rochelle is the standard drainage surgery.

Consensus Levels of Agreement:

$\mathrm{A}+84.8 \%$; A $10.9 \% ; \mathrm{A}-2.2 \% ; \mathrm{D}-2.2 \%$; $0 \%$; D $0 \%$

Lateral pancreatico-jejunostomy (LPJ) was proposed by Partington and Rochelle. It consists in a complete opening of the pancreatic duct up to one centimeter from the papilla of Vater and a side-to-side pancreatico-jejunostomy by means of a Roux-en-Y jejunal loop anastomized to the pancreatic duct. LPJ has replaced Puestow's operation. A wide drainage of the entire pancreatic duct is recommended and the length of the anastomosis is crucial for long-term outcome [271-274]. Therefore, the pancreatic duct must be opened completely and a long lateral pancreatico-jejunostomy must be performed to achieve complete drainage, avoiding a too short pancreaticojejunostomy.

LPJ provides a good pain relief $(80 \%)$ and a good preservation of endocrine and exocrine pancreatic function [275]. Moreover it is associated with low mortality and morbidity rates [276-278]. In a prospective study, Maartense [103] compared DPHR vs. LPJ and observed an improvement of endocrine function after LPJ. However, LPJ has not been evaluated in RCTs, even if it is widely used.

S.9: When is a mixed surgery (drainage + limited resection) indicated?

Statement (EL 1b - RG A): A mixed surgery is indicated in case of head mass-forming chronic pancreatitis, with or without biliary tract involvement.

Consensus Levels of Agreement:

A+ 58.7\%; A 23.9\%; A- 10.9\%; D-2.2\%; D 2.2\%; D $2.2 \%$

Different procedures that combine drainage and limited resection have been proposed (DPHR, LR-LPJ, Berne procedure, V-shape operation) [279-282]. The mixed operations should be the ideal interventions for chronic pancreatitis because they combine resection with drainage and theoretically 
may offer in a single operation: (a) better drainage of the pancreatic ducts; (b) partial removal of the inflammatory mass in the pancreatic head; (c) resolution of biliary tract obstruction; (d) reduction of pancreatic parenchymal loss.

A recent meta-analysis [283], some RCTs [228,232,284] and a recent review [266] have demonstrated the effectiveness of such procedures. DPHR, LR-LPJ and Berne operation are indicated when an inflammatory enlargement of the pancreatic head has been found with or without dilation of the ductal system. In LR-LPJ a coring-out excision of the pancreatic head and uncinate process is performed, the pancreatic duct is completely opened and a lateral pancreatico-jejunostomy is performed. LR-LPJ may be chosen when the main pancreatic duct is uniformly dilated or it appears like "chain of lakes" and it could be performed also in the absence of a great enlargement of the pancreatic head. DPHR consists of a subtotal resection of the head of the pancreas conserving the duodenum with a rim of pancreatic parenchyma and including a complete division of pancreatic gland at the neck. Therefore the restoration of the exocrine pancreatic secretory flow from the body and tail of the pancreas is performed by using the first jejunal loop as an interposition.

The Berne procedure is similar to DPHR, but avoids the dangerous division of the pancreatic neck above the portal vein, leaving a sheet of pancreatic parenchyma over the vein, so it is safe in the case of portal hypertension [281]. Probably, mixed operations have the best long-term results [266], but no RCT has compared mixed and drainage operations, and the better results of mixed operations are in comparison with old drainage series. Moreover, mixed operations are demanding techniques which require a higher surgical skill than LPJ.

S.10: What is considered the mixed procedure (drainage + limited resection) of choice?

Statement (EL 1b - RG A): Local resection-lateral pancreatico-jejunostomy (LR-LPJ), duodenum-preserving head resection (DPHR) or Berne operation have similar results. The choice among these surgical procedures is based on the surgeon's experience.

Statement (EL 3a - RG B): V-shaped operation is the treatment of choice when small-duct disease is present along the pancreatic duct without an inflammatory mass. Consensus Levels of Agreement:

A+67.3\%; A 24.5\%; A-6.1\%; D-2\%; D 0\%; D+ 0\%

Some RCTs have analyzed the results of the mixed procedures. Two RCTs [284,285] compared LR-LPJ vs. DPHR and showed similar short-term and long-term results for pain relief, pancreatic function, mortality rates and quality of life. LR-LPJ is technically easier to perform than DPHR because it does not require the section of the neck of the pancreas [286].

One RCT compared Berne vs. DPHR [233]. The results for quality of life did not differ significantly, but the Berne procedure is easier to perform and avoids the dangerous division of the pancreatic neck above the portal vein.
Moreover it presents shorter operation time and hospital stay. V-shaped operation, consisting in a triangular excision of the entire anterior aspect of the pancreas with longitudinal pancreatico-jejunostomy, is indicated when small-duct disease is present along all the pancreatic duct without inflammatory mass [233]. V-shaped operation is a safe and effective treatment for small-duct disease with median pain score decreased by $95 \%$ at follow-up [287].

S.11: When is pancreatico-duodenectomy (PD) indicated in chronic pancreatitis?

Statement (EL 5 - RG D): Pancreatico-duodenectomy is mandatory in patients with chronic pancreatitis when cancer of the pancreatic head is not ruled out.

Statement (EL 1b - RG A): It can be indicated also in case of pancreatic head mass, as an alternative to mixed surgery.

Consensus Levels of Agreement:

A+60\%; A $22.2 \%$; A- 8.9\%; D- $0 \%$; D 4.4\%; D+4.4\%

Generally PD has good results in the treatment of chronic pancreatitis [230,234,288-293]. However, with the advent of the mixed techniques the role of the PD has been discussed.

Some RCTs and prospective studies have been published comparing classical PD or PPPD vs. mixed techniques. Mixed techniques have equal pain relief and better short-term outcome than PD [229,230,293,294] while results in longterm follow-up are similar [295,296].

Although mixed procedures represent the rational approach to chronic pancreatitis, PD remains the most widely used surgical intervention [297].

S.12: When is distal pancreatectomy (DP) indicated? Statement (EL 4 - RG C): Distal pancreatectomy is indicated when chronic pancreatitis mainly involves the left side of the pancreas.

Statement (EL 4 - RG C): It is mandatory in case of tail cancer suspicion.

Consensus Levels of Agreement:

$\mathrm{A}+77.6 \%$; A $12.2 \%$; A-8.2\%; D-2.2\%; D 0\%; D+ 0\%

Today DP is rarely performed in chronic pancreatitis and few data are available from the last 10 years [298-300]. In the past a high incidence of failure on pain relief after DP was reported, with only $31 \%$ of good results [301]. This may be due to poor patient selection. When DP was performed with strict indication for predominantly left-side disease, obstructive chronic pancreatitis or large pseudocyst $[302,303]$ pain relief was found in $88-90 \%$ of patients. Moreover, DP is mandatory in the suspicion of tail cancer or for a pseudocyst with concomitant bleeding. When splenectomy is indicated for left-side portal hypertension, DP is the intervention of choice. A pancreatico-jejunostomy should be performed to drain the pancreatic stump after DP [299]. 
S.13: When should total pancreatectomy be considered in chronic pancreatitis?

Statement (EL 4 - RG C): Total pancreatectomy should be considered after failure of previous surgery.

Consensus Levels of Agreement:

A+71\%; A 24.4\%; A-6.1\%; D- $0 \%$; D 0\%; D+ 2\%

There is no prospective randomised study comparing total pancreatectomy with other surgical treatments. In highvolume pancreatic surgery centers, total (or near-total) pancreatectomy can be performed with low mortality rate [304306], and seems to be effective in improving symptoms in painful chronic pancreatitis [304,305,307-309]. The major drawback of this operation is the "brittle" post-surgical diabetes, with difficult management owing to the absence of counterregulatory hormones. To resolve this problem, islet auto transplantation (IAT) has been proposed. Concomitant IAT allows milder surgical diabetes, with a variable reported percentage of short-term insulin independence, according to the experience of different centers (from $0 \%$ to $55 \%$ [305]). One third of 55 patients treated with total pancreatectomy and IAT at the University of Minnesota were insulin-independent after ten years [305].

S.14: When should intraoperative frozen section be done in a patient with chronic pancreatitis?

Statement (EL 5 - RG D): Frozen sections' examination is indicated when pancreatic ductal carcinoma (PDC) or intraductal papillary mucinous neoplasm (IPMN) are intraoperatively suspected.

Consensus Levels of Agreement:

$\mathrm{A}+73.9 \%$; A $15.2 \%$; A-2.2\%; D-6.5\%; D 0\%; D+2.2\%

Differential diagnosis between chronic pancreatitis and PDC based on frozen sections could be extremely difficult, with false negative and positive rates ranging from $10 \%$ to $30 \%$ [310]. To reach a correct diagnosis, the knowledge of clinico-radiological data and the submission of multiple biopsies is crucial, including lymph nodes or any other suspicious lesion [311]. In PDC, the most important pathological criteria are the loss of a lobular pattern, the presence of angular contours with ruptured ducts, intraluminar debris, the presence of solitary "naked" ducts in the fat tissue, and the extrapancreatic infiltration with perineural and vascular invasion [312,313]. Unfortunately, chronic pancreatitis and PDC may sometimes look very similar, especially in case of a well differentiated carcinoma.

The differential diagnosis between chronic pancreatitis and IPMN is based on the presence or absence of dysplastic modification either in the main duct or in the branch ducts [314]. Nevertheless, some limitations must be considered: (1) differential diagnosis between hyperplasia and low-grade dysplasia can be difficult (only moderate-high grade dysplasia can be detected on frozen sections) [315]; (2) extensive inflammatory reaction with epithelial denudation is frequently found in association with dilatation of the main duct both in chronic pancreatitis and in IPMN. The submission of additional biopsies in the search of the lining epithelium has to be considered, when possible. However, in case of strong clinical suspicion and negative intraoperative pathological results, a standard resection is recommended.

\section{Conclusion}

These statements represent the first comprehensive and practical guidelines for the management of chronic pancreatitis. They resulted from a critical appraisal of the best available evidence, and from expertise. A consensus process contributed to their elaboration. This allowed to elaborate in sequential steps the statements, to define a level of evidence, to attribute a strength of recommendation, and to appreciate the degree of agreement, making clinicians aware about their quality and reliability.

Eighty-three per cent of statements received an agreement rate of at least $80 \%$. While still at over $67 \%$ agreement rate, some topics (17\%) did not reach such high agreement rate, for instance, prevention of pain with antioxidants, role of smoking withdrawal in pain control, function test and diagnosis of the disease, size of risk of pancreatic cancer, but also surgery in asymptomatic patients and duct obstruction, surgery in the treatment of jaundice, and imaging in pancreatic stones.

The systematic analysis and appraisal of literature showed that the level of evidence in this disease is high or good (evidence level 1-2) for almost $40 \%$ of the statements, but it remains moderate or low in some areas, such as imaging and surgery, though excellent papers have been published on some specific surgical topics. A or B strength of recommendation was attributed to $45 \%$ of the statements. However, available knowledge is represented by expert opinion in almost $20 \%$ of the statements.

These guidelines represent a useful tool for approaching chronic pancreatitis in a clinical setting. However, the comprehensive process of their elaboration clearly suggested that further clinical research, better in quality, is needed for the management of chronic pancreatitis.

\section{Participants to the Consensus Conference}

The following were participants at the Consensus Meeting held in Verona on $16^{\text {th }}$ and $17^{\text {th }}$ November 2009 to discuss the guidelines, and made active contributions to their formulation: Luca Albarello (Milano), Sergio Alfieri (Roma), Antonio Amodio (Verona), Angelo Andriulli (San Giovanni Rotondo), Marcello Anti (Viterbo), Piergiorgio Arcidiacono (Milano), Luca Baiocchi (Brescia), Gianpaolo Balzano (Milano), Luigi Benini (Verona), Debora Berretti (Udine), Pietro Boraschi (Pisa), Elisabetta Buscarini (Crema), Lucia Calculli (Bologna), Antonio Carroccio (Palermo), Donata Campra (Torino), Mario Roberto Celebrano (Verona), Gabriele Capurso (Roma), Riccardo Casadei (Bologna), Giulia Martina Cavestro (Parma), Fausto Chilovi (Bolzano), Rita Conegliaro (Modena), Luigi Dall'Oglio (Roma), Claudio De Angelis (Torino), Michele De Boni (Feltre), Giovanni De Pretis (Trento), Sebastiano Di Priolo (Cagli), Pier Luigi Di Sebastiano (San Giovanni Rotondo), Giovanni Battista Doglietto 
(Roma), Massimo Falconi (Verona), Marco Filauro (Genova), Giuseppe Frieri (L'Aquila), Luca Frulloni (Verona), Arnaldo Fuini (Verona), Ezio Gaia (Torino), Luigi Ghezzo (Cuneo), Armando Gabbrielli (Verona), Rossella Graziani (Verona), Pietro Loriga (Cagliari), Giampiero Macarri (Fermo), Gianpiero Manes (Milano), Riccardo Manfredi (Verona), Alberto Malesci (Milano), Alberto Mariani (Milano), Paolo Massucco (Torino), Stefano Milani (Firenze), Massimiliano Mutignani (Roma), Claudio Pasquali (Padova), Paolo Pederzoli (Verona), Raffaele Pezzilli (Bologna), Michele Pietrangeli (Cagliari), Rodolfo Rocca (Torino), Domenico Russello (Catania), Walter Siquini (Ancona), Mario Traina (Palermo), Generoso Uomo (Napoli), Luigi Veneroni (Rimini), Maurizio Ventrucci (Bentivoglio), Maurizio Zilli (Udine), Giuseppe Zamboni (Verona).

\section{Funding sources}

The organization of the Working parties and Consensus meeting was supported by Abbott Products SpA.

With respect to the voting process, $100 \%$ of participants agreed that the sponsor had no influence whatsoever on their vote.

\section{Conflict of interest statement}

The authors have no conflict of interest to report.

\section{Acknowledgements}

The authors thank Nicoletta Pasqui and Irene Grazioli (Medical Department, Abbott Products SpA) for the scientific and organization support.

\section{References}

[1] Guidelines for the diagnosis and treatment of chronic pancreatitis (Nanjing, 2005). Chin J Dig Dis 2005;6:198-201.

[2] Warshaw AL, Banks PA, Fernandez-Del Castillo C. AGA technical review: treatment of pain in chronic pancreatitis. Gastroenterology 1998; 115:765-76.

[3] Tandon RK, Sato N, Garg PK. Chronic pancreatitis: Asia-Pacific consensus report. J Gastroenterol Hepatol 2002;17:508-18.

[4] American Society for Gastrointestinal Endoscopy. Endoscopic therapy of chronic pancreatitis. Gastrointest Endosc 2000;52:843-8.

[5] Tringali A, Boskoski I, Costamagna G. The role of endoscopy in the therapy of chronic pancreatitis. Best Pract Res Clin Gastroenterol 2008;22:145-65.

[6] Meier R, Ockenga J, Pertkiewicz M, et al. ESPEN Guidelines on Enteral Nutrition: Pancreas. Clin Nutr 2006;25:275-84.

[7] Kamisawa T, Anjiki H, Takuma K, et al. The natural course of autoimmune pancreatitis. Hepatogastroenterology 2009;56:866-70.

[8] Frulloni L, Scattolini C, Falconi M, et al. Autoimmune pancreatitis: differences between the focal and diffuse forms in 87 patients. Am J Gastroenterol 2009;104:2288-94.

[9] Chari ST, Longnecker DS, Kloppel G. The diagnosis of autoimmune pancreatitis: a Western perspective. Pancreas 2009;38:846-8.

[10] Buscarini E, Frulloni L, De Lisi S, et al. Autoimmune pancreatitis: a challenging diagnostic puzzle for clinicians. Dig Liver Dis 2010;42: 92-8.

[11] Witt H, Luck W, Hennies HC, et al. Mutations in the gene encoding the serine protease inhibitor, Kazal type 1 are associated with chronic pancreatitis. Nat Genet 2000;25:213-6.
[12] Layer P, Yamamoto H, Kalthoff L, et al. The different courses of early- and late-onset idiopathic and alcoholic chronic pancreatitis. Gastroenterology 1994;107:1481-7.

[13] Cohn JA, Friedman KJ, Noone PG, et al. Relation between mutations of the cystic fibrosis gene and idiopathic pancreatitis. N Engl J Med 1998;339:653-8.

[14] Frulloni L, Castellani C, Bovo P, et al. Natural history of pancreatitis associated with cystic fibrosis gene mutations. Dig Liver Dis 2003;35: 179-85.

[15] Sharer N, Schwarz M, Malone G, et al. Mutations of the cystic fibrosis gene in patients with chronic pancreatitis. N Engl J Med 1998;339: 645-52.

[16] Steer ML, Waxman I, Freedman S. Chronic pancreatitis. N Engl J Med 1995;332:1482-90.

[17] Wang LW, Li ZS, Li SD, et al. Prevalence and clinical features of chronic pancreatitis in China: a retrospective multicenter analysis over 10 years. Pancreas 2009;38:248-54.

[18] Witt H, Apte MV, Keim V, et al. Chronic pancreatitis: challenges and advances in pathogenesis, genetics, diagnosis, and therapy. Gastroenterology 2007;132:1557-73.

[19] Ammann RW, Muellhaupt B. The natural history of pain in alcoholic chronic pancreatitis. Gastroenterology 1999;116:1132-40.

[20] Niemann T, Madsen LG, Larsen S, et al. Opioid treatment of painful chronic pancreatitis. Int J Pancreatol 2000;27:235-40.

[21] Bourliere M, Barthet M, Berthezene P, et al. Is tobacco a risk factor for chronic pancreatitis and alcoholic cirrhosis? Gut 1991;32:1392-5.

[22] Lin Y, Tamakoshi A, Hayakawa T, et al. Cigarette smoking as a risk factor for chronic pancreatitis: a case-control study in Japan. Research Committee on Intractable Pancreatic Diseases. Pancreas 2000; 21:109-14.

[23] Lowenfels AB, Zwemer FL, Jhangiani S, et al. Pancreatitis in a native American Indian population. Pancreas 1987;2:694-7.

[24] Morton C, Klatsky AL, Udaltsova N. Smoking, coffee, and pancreatitis. Am J Gastroenterol 2004;99:731-8.

[25] Nakamura Y, Kobayashi Y, Ishikawa A, et al. Severe chronic pancreatitis and severe liver cirrhosis have different frequencies and are independent risk factors in male Japanese alcoholics. J Gastroenterol 2004;39:879-87.

[26] Rothenbacher D, Low M, Hardt PD, et al. Prevalence and determinants of exocrine pancreatic insufficiency among older adults: results of a population-based study. Scand J Gastroenterol 2005;40:697-704.

[27] Bloechle C, Izbicki JR, Knoefel WT, et al. Quality of life in chronic pancreatitis - results after duodenum-preserving resection of the head of the pancreas. Pancreas 1995;11:77-85.

[28] Talamini G, Vaona B, Bassi C, et al. Alcohol intake, cigarette smoking, and body mass index in patients with alcohol-associated pancreatitis. J Clin Gastroenterol 2000;31:314-7.

[29] Wilder-Smith CH, Hill L, Osler W, et al. Effect of tramadol and morphine on pain and gastrointestinal motor function in patients with chronic pancreatitis. Dig Dis Sci 1999;44:1107-16.

[30] Yen S, Hsieh CC, MacMahon B. Consumption of alcohol and tobacco and other risk factors for pancreatitis. Am J Epidemiol 1982;116: 407-14.

[31] Talamini G, Bassi C, Falconi $M$, et al. Cigarette smoking: an independent risk factor in alcoholic pancreatitis. Pancreas 1996;12:131-7.

[32] Imoto M, DiMagno EP. Cigarette smoking increases the risk of pancreatic calcification in late-onset but not early-onset idiopathic chronic pancreatitis. Pancreas 2000;21:115-9.

[33] Maisonneuve P, Lowenfels AB, Mullhaupt B, et al. Cigarette smoking accelerates progression of alcoholic chronic pancreatitis. Gut 2005;54: 510-4.

[34] Ammann RW, Heitz PU, Kloppel G. Course of alcoholic chronic pancreatitis: a prospective clinicomorphological long-term study. Gastroenterology 1996;111:224-31.

[35] Ammann RW, Muellhaupt B. Progression of alcoholic acute to chronic pancreatitis. Gut 1994;35:552-6.

[36] Cahen DL, Gouma DJ, Nio Y, et al. Endoscopic versus surgical drainage 
of the pancreatic duct in chronic pancreatitis. N Engl J Med 2007;356: 676-84.

[37] Gullo L, Barbara L, Labo G. Effect of cessation of alcohol use on the course of pancreatic dysfunction in alcoholic pancreatitis. Gastroenterology 1988;95:1063-8.

[38] Hayakawa T, Kondo T, Shibata T, et al. Chronic alcoholism and evolution of pain and prognosis in chronic pancreatitis. Dig Dis Sci 1989;34:33-8.

[39] Mullhaupt B, Truninger K, Ammann R. Impact of etiology on the painful early stage of chronic pancreatitis: a long-term prospective study. Z Gastroenterol 2005;43:1293-301.

[40] Thuluvath PJ, Imperio D, Nair S, et al. Chronic pancreatitis. Long-term pain relief with or without surgery, cancer risk, and mortality. J Clin Gastroenterol 2003;36:159-65.

[41] Bueno de Mesquita HB, Maisonneuve P, Moerman CJ, et al. Aspects of medical history and exocrine carcinoma of the pancreas: a populationbased case-control study in The Netherlands. Int J Cancer 1992;52: $17-23$.

[42] Farrow DC, Davis S. Risk of pancreatic cancer in relation to medical history and the use of tobacco, alcohol and coffee. Int J Cancer 1990; 45:816-20.

[43] Fernandez E, La Vecchia C, Porta M, et al. Pancreatitis and the risk of pancreatic cancer. Pancreas 1995;11:185-9.

[44] Gold EB, Gordis L, Diener MD, et al. Diet and other risk factors for cancer of the pancreas. Cancer 1985;55:460-7.

[45] Jain M, Howe GR, St Louis P, et al. Coffee and alcohol as determinants of risk of pancreas cancer: a case-control study from Toronto. Int J Cancer 1991;47:384-9.

[46] Kalapothaki V, Tzonou A, Hsieh CC, et al. Tobacco, ethanol, coffee, pancreatitis, diabetes mellitus, and cholelithiasis as risk factors for pancreatic carcinoma. Cancer Causes Control 1993;4:375-82.

[47] La Vecchia C, Negri E, D'Avanzo B, et al. Medical history, diet and pancreatic cancer. Oncology 1990;47:463-6.

[48] Lin RS, Kessler, II. A multifactorial model for pancreatic cancer in man. Epidemiologic evidence. JAMA 1981;245:147-52.

[49] Mack TM, Yu MC, Hanisch R, et al. Pancreas cancer and smoking, beverage consumption, and past medical history. J Natl Cancer Inst 1986;76:49-60.

[50] Wynder EL, Mabuchi K, Maruchi N, et al. Epidemiology of cancer of the pancreas. J Natl Cancer Inst 1973;50:645-67.

[51] Bansal P, Sonnenberg A. Pancreatitis is a risk factor for pancreatic cancer. Gastroenterology 1995;109:247-51.

[52] Chari ST, Mohan V, Pitchumoni CS, et al. Risk of pancreatic carcinoma in tropical calcifying pancreatitis: an epidemiologic study. Pancreas 1994;9:62-6.

[53] Ekbom A, McLaughlin JK, Karlsson BM, et al. Pancreatitis and pancreatic cancer: a population-based study. J Natl Cancer Inst 1994;86:625-7.

[54] Kamisawa T, Tu Y, Egawa N, et al. The incidence of pancreatic and extrapancreatic cancers in Japanese patients with chronic pancreatitis. Hepatogastroenterology 2007;54:1579-81.

[55] Karlson BM, Ekbom A, Josefsson S, et al., Nyren O. The risk of pancreatic cancer following pancreatitis: an association due to confounding? Gastroenterology 1997;113:587-92.

[56] Lowenfels AB, Maisonneuve P, Cavallini G, et al. Pancreatitis and the risk of pancreatic cancer. International Pancreatitis Study Group. N Engl J Med 1993;328:1433-7.

[57] Malka D, Hammel P, Maire F, et al. Risk of pancreatic adenocarcinoma in chronic pancreatitis. Gut 2002;51:849-52.

[58] Otsuki M, Tashiro M. 4. Chronic pancreatitis and pancreatic cancer, lifestyle-related diseases. Intern Med 2007;46:109-13.

[59] Rocca G, Gaia E, Iuliano R, et al. Increased incidence of cancer in chronic pancreatitis. J Clin Gastroenterol 1987;9:175-9.

[60] Talamini G, Falconi M, Bassi C, et al. Incidence of cancer in the course of chronic pancreatitis. Am J Gastroenterol 1999;94:1253-60.

[61] Czako L, Takacs T, Hegyi P, et al. Quality of life assessment after pancreatic enzyme replacement therapy in chronic pancreatitis. Can J Gastroenterol 2003;17:597-603.
[62] Fitzsimmons D, Kahl S, Butturini G, et al. Symptoms and quality of life in chronic pancreatitis assessed by structured interview and the EORTC QLQ-C30 and QLQ-PAN26. Am J Gastroenterol 2005;100:918-26.

[63] Kirk GR, White JS, McKie L, et al. Combined antioxidant therapy reduces pain and improves quality of life in chronic pancreatitis. $J$ Gastrointest Surg 2006;10:499-503.

[64] Pezzilli R, Bini L, Fantini L, et al. Quality of life in chronic pancreatitis. World J Gastroenterol 2006;12:6249-51.

[65] Pezzilli R, Morselli Labate AM, Ceciliato R, et al. Quality of life in patients with chronic pancreatitis. Dig Liver Dis 2005;37:181-9.

[66] Pezzilli R, Morselli-Labate AM, Fantini L, et al. Assessment of the quality of life in chronic pancreatitis using SF-12 and EORTC Qlq-C30 questionnaires. Dig Liver Dis 2007;39:1077-86.

[67] Pezzilli R, Morselli-Labate AM, Frulloni L, et al. The quality of life in patients with chronic pancreatitis evaluated using the SF-12 questionnaire: a comparative study with the SF-36 questionnaire. Dig Liver Dis 2006;38:109-15.

[68] Wehler M, Nichterlein R, Fischer B, et al. Factors associated with health-related quality of life in chronic pancreatitis. Am J Gastroenterol 2004;99:138-46.

[69] Wehler M, Reulbach U, Nichterlein R, et al. Health-related quality of life in chronic pancreatitis: a psychometric assessment. Scand J Gastroenterol 2003;38:1083-9.

[70] Sommer H, Kasper H. Effect of long-term administration of dietary fiber on the exocrine pancreas in the rat. Hepatogastroenterology 1984; 31:176-9.

[71] Isaksson G, Lilja P, Lundquist I, et al. Influence of dietary fiber on exocrine pancreatic function in the rat. Digestion 1983;27:57-62.

[72] Dutta SK, Hlasko J. Dietary fiber in pancreatic disease: effect of high fiber diet on fat malabsorption in pancreatic insufficiency and in vitro study of the interaction of dietary fiber with pancreatic enzymes. Am J Clin Nutr 1985;41:517-25.

[73] Caliari S, Benini L, Sembenini C, et al. Medium-chain triglyceride absorption in patients with pancreatic insufficiency. Scand J Gastroenterol 1996;31:90-4.

[74] Caliari S, Benini L, Bonfante F, et al. Pancreatic extracts are necessary for the absorption of elemental and polymeric enteral diets in severe pancreatic insufficiency. Scand J Gastroenterol 1993;28:749-52.

[75] Singh S, Midha S, Singh N, et al. Dietary counseling versus dietary supplements for malnutrition in chronic pancreatitis: a randomized controlled trial. Clin Gastroenterol Hepatol 2008;6:353-9.

[76] Dutta SK, Bustin MP, Russell RM, et al. Deficiency of fat-soluble vitamins in treated patients with pancreatic insufficiency. Ann Intern Med 1982;97:549-52.

[77] Forsmark CE. Chronic pancreatitis and malabsorption. Am J Gastroenterol 2004;99:1355-7.

[78] Moran CE, Sosa EG, Martinez SM, et al. Bone mineral density in patients with pancreatic insufficiency and steatorrhea. Am J Gastroenterol 1997;92:867-71.

[79] Haaber AB, Rosenfalck AM, Hansen B, et al. Bone mineral metabolism, bone mineral density, and body composition in patients with chronic pancreatitis and pancreatic exocrine insufficiency. Int J Pancreatol 2000;27:21-7.

[80] Bhardwaj P, Garg PK, Maulik SK, et al. A randomized controlled trial of antioxidant supplementation for pain relief in patients with chronic pancreatitis. Gastroenterology 2009;136:149-159 e2.

[81] Durgaprasad S, Pai CG, Vasanthkumar, et al. A pilot study of the antioxidant effect of curcumin in tropical pancreatitis. Indian J Med Res 2005;122:315-8.

[82] De las Heras Castano G, Garcia de la Paz A, Fernandez MD, et al. Use of antioxidants to treat pain in chronic pancreatitis. Rev Esp Enferm Dig 2000;92:375-85.

[83] Banks PA, Hughes M, Ferrante M, et al. Does allopurinol reduce pain of chronic pancreatitis? Int J Pancreatol 1997;22:171-6.

[84] Uden S, Schofield D, Miller PF, et al. Antioxidant therapy for recurrent pancreatitis: biochemical profiles in a placebo-controlled trial. Aliment Pharmacol Ther 1992;6:229-40.

[85] Uden S, Bilton D, Nathan L, et al. Antioxidant therapy for recurrent 
pancreatitis: placebo-controlled trial. Aliment Pharmacol Ther 1990;4: $357-71$.

[86] Dominguez-Munoz JE. Pancreatic enzyme therapy for pancreatic exocrine insufficiency. Curr Gastroenterol Rep 2007;9:116-22.

[87] Waljee AK, Dimagno MJ, Wu BU, et al. Systematic review: pancreatic enzyme treatment of malabsorption associated with chronic pancreatitis. Aliment Pharmacol Ther 2009;29:235-46.

[88] Dominguez-Munoz JE, Iglesias-Garcia J, Vilarino-Insua M, et al. 13Cmixed triglyceride breath test to assess oral enzyme substitution therapy in patients with chronic pancreatitis. Clin Gastroenterol Hepatol 2007; 5:484-8.

[89] Dumasy V, Delhaye M, Cotton F, et al. Fat malabsorption screening in chronic pancreatitis. Am J Gastroenterol 2004;99:1350-4.

[90] Malesci A, Gaia E, Fioretta A, et al. No effect of long-term treatment with pancreatic extract on recurrent abdominal pain in patients with chronic pancreatitis. Scand J Gastroenterol 1995;30:392-8.

[91] Brown A, Hughes M, Tenner S, et al. Does pancreatic enzyme supplementation reduce pain in patients with chronic pancreatitis: a meta-analysis. Am J Gastroenterol 1997;92:2032-5.

[92] Dominguez-Munoz JE, Iglesias-Garcia J, Iglesias-Rey $M$, et al. Optimising the therapy of exocrine pancreatic insufficiency by the association of a proton pump inhibitor to enteric coated pancreatic extracts. Gut 2006;55:1056-7.

[93] Delhaye M, Meuris S, Gohimont AC, et al. Comparative evaluation of a high lipase pancreatic enzyme preparation and a standard pancreatic supplement for treating exocrine pancreatic insufficiency in chronic pancreatitis. Eur J Gastroenterol Hepatol 1996;8:699-703.

[94] Nakamura T, Arai Y, Tando Y, et al. Effect of omeprazole on changes in gastric and upper small intestine $\mathrm{pH}$ levels in patients with chronic pancreatitis. Clin Ther 1995;17:448-59.

[95] Layer P, Keller J, Lankisch PG. Pancreatic enzyme replacement therapy. Curr Gastroenterol Rep 2001;3:101-8.

[96] Kuhnelt P, Mundlos S, Adler G. [Effect of pellet size of a pancreas enzyme preparation on duodenal lipolytic activity]. Z Gastroenterol 1991;29:417-21.

[97] Safdi M, Bekal PK, Martin S, et al. The effects of oral pancreatic enzymes (Creon 10 capsule) on steatorrhea: a multicenter, placebocontrolled, parallel group trial in subjects with chronic pancreatitis. Pancreas 2006;33:156-62.

[98] Dominguez-Munoz JE, Iglesias-Garcia J, Iglesias-Rey M, et al. Effect of the administration schedule on the therapeutic efficacy of oral pancreatic enzyme supplements in patients with exocrine pancreatic insufficiency: a randomized, three-way crossover study. Aliment Pharmacol Ther 2005;21:993-1000.

[99] Vague P, Nguyen L. Rationale and methods for the estimation of insulin secretion in a given patient: from research to clinical practice. Diabetes 2002;51 Suppl 1:S240-4.

[100] Wakasugi H, Funakoshi A, Iguchi H. Clinical assessment of pancreatic diabetes caused by chronic pancreatitis. J Gastroenterol 1998;33:254-9.

[101] von Tirpitz C, Glasbrenner B, Mayer D, et al. Comparison of different endocrine stimulation tests in nondiabetic patients with chronic pancreatitis. Hepatogastroenterology 1998;45:1111-6.

[102] Goke B, Goke R. New classes of antidiabetic drugs: new perspectives for diabetes mellitus treatment. In: Büchler M, Friess H, Uhl W, Malfertheiner P, eds. Chronic Pancreatitis: novel concepts in biology and therapy. Oxford: Blackwell Scieces Ltd, 2002.

[103] Maartense S, Ledeboer M, Bemelman WA, et al. Effect of surgery for chronic pancreatitis on pancreatic function: pancreatico-jejunostomy and duodenum-preserving resection of the head of the pancreas. Surgery 2004;135:125-30.

[104] Matsumoto J, Traverso LW. Exocrine function following the whipple operation as assessed by stool elastase. J Gastrointest Surg 2006;10: 1225-9.

[105] Chowdhury RS, Forsmark CE. Review article: Pancreatic function testing. Aliment Pharmacol Ther 2003;17:733-50.

[106] Niederau C, Grendell JH. Diagnosis of chronic pancreatitis. Gastroenterology 1985;88:1973-95.
[107] Lankisch PG, Schmidt I, Konig H, et al. Faecal elastase 1: not helpful in diagnosing chronic pancreatitis associated with mild to moderate exocrine pancreatic insufficiency. Gut 1998;42:551-4.

[108] Naruse S, Ishiguro H, Ko SB, et al. Fecal pancreatic elastase: a reproducible marker for severe exocrine pancreatic insufficiency. J Gastroenterol 2006;41:901-8.

[109] Symersky T, van der Zon A, Biemond I, et al. Faecal elastase-I: helpful in analysing steatorrhoea? Neth J Med 2004;62:286-9.

[110] Parsi MA, Conwell DL, Zuccaro G, et al. Findings on endoscopic retrograde cholangiopancreatography and pancreatic function test in suspected chronic pancreatitis and negative cross-sectional imaging. Clin Gastroenterol Hepatol 2008;6:1432-6.

[111] Stevens T, Conwell DL, Zuccaro G, et al., Van Lente F, Lopez R, Purich E, Fein S. A prospective crossover study comparing secretinstimulated endoscopic and Dreiling tube pancreatic function testing in patients evaluated for chronic pancreatitis. Gastrointest Endosc 2008; 67:458-66.

[112] Forsmark CE. The early diagnosis of chronic pancreatitis. Clin Gastroenterol Hepatol 2008;6:1291-3.

[113] Gullo L, Ventrucci M, Tomassetti P, et al. Fecal elastase 1 determination in chronic pancreatitis. Dig Dis Sci 1999;44:210-3.

[114] Etemad B, Whitcomb DC. Chronic pancreatitis: diagnosis, classification, and new genetic developments. Gastroenterology 2001;120:682-707.

[115] Adamek HE, Jakobs R, Buttmann A, et al. Long term follow up of patients with chronic pancreatitis and pancreatic stones treated with extracorporeal shock wave lithotripsy. Gut 1999;45:402-5.

[116] Tsao TF, Kang RJ, Tyan YS, et al. Color Doppler twinkling artifact related to chronic pancreatitis with parenchymal calcification. Acta Radiol 2006;47:547-8.

[117] Shams J, Stein A, Cooperman AM. Computed tomography for pancreatic diseases. Surg Clin North Am 2001;81:283-306.

[118] Kalra MK, Maher MM, Sahani DV, et al. Current status of imaging in pancreatic diseases. J Comput Assist Tomogr 2002;26:661-75.

[119] Graziani R, Tapparelli M, Malago R, et al. The various imaging aspects of chronic pancreatitis. JOP 2005;6:73-88.

[120] Karasawa Y, Kawa S, Aoki Y, et al. Extracorporeal shock wave lithotripsy of pancreatic duct stones and patient factors related to stone disintegration. J Gastroenterol 2002;37:369-75.

[121] Chari ST. Chronic pancreatitis: classification, relationship to acute pancreatitis, and early diagnosis. J Gastroenterol 2007;42 Suppl 17:58-9.

[122] Robinson PJ, Sheridan MB. Pancreatitis: computed tomography and magnetic resonance imaging. Eur Radiol 2000;10:401-8.

[123] Rhee J, Scheiman J, Inadomi J. "Spontaneous" passage of a pancreatic duct stone. Gastrointest Endosc 2003;57:278-80.

[124] Page JM, Vinson SL, Jones DP. Complex pancreatic duct stricture with stone versus partial pancreas divisum: a therapeutic dilemma. Dig Dis Sci 2007;52:1621-6.

[125] Hashimoto A, Moritani I, Shimizu A, et al. Education and imaging. Hepatobiliary and pancreatic: oral therapy for pancreatic duct stones. J Gastroenterol Hepatol 2006;21:1496.

[126] Siddiqi AJ, Miller F. Chronic pancreatitis: ultrasound, computed tomography, and magnetic resonance imaging features. Semin Ultrasound CT MR 2007;28:384-94.

[127] Elmas N. The role of diagnostic radiology in pancreatitis. Eur J Radiol 2001;38:120-32.

[128] Remer EM, Baker ME. Imaging of chronic pancreatitis. Radiol Clin North Am 2002;40:1229-42, v.

[129] Chaya CT, Bhutani MS. Ultrasonography of the pancreas. 6. Endoscopic imaging. Abdom Imaging 2007;32:191-9.

[130] Kwon RS, Brugge WR. New advances in pancreatic imaging. Curr Opin Gastroenterol 2005;21:561-7.

[131] Hakime A, Giraud M, Vullierme MP, et al. [MR imaging of the pancreas]. J Radiol 2007;88:11-25.

[132] Matos C, Metens T, Deviere J, et al. Pancreatic duct: morphologic and functional evaluation with dynamic MR pancreatography after secretin stimulation. Radiology 1997;203:435-41. 
[133] Balci NC, Alkaade S, Magas L, et al. Suspected chronic pancreatitis with normal MRCP: findings on MRI in correlation with secretin MRCP. J Magn Reson Imaging 2008;27:125-31.

[134] Calculli L, Pezzilli R, Fiscaletti M, et al. Exocrine pancreatic function assessed by secretin cholangio-Wirsung magnetic resonance imaging. Hepatobiliary Pancreat Dis Int 2008;7:192-5.

[135] Czako L. Diagnosis of early-stage chronic pancreatitis by secretin-enhanced magnetic resonance cholangiopancreatography. J Gastroenterol 2007;42 Suppl 17:113-7.

[136] Gillams AR, Lees WR. Quantitative secretin MRCP (MRCPQ): results in 215 patients with known or suspected pancreatic pathology. Eur Radiol 2007;17:2984-90.

[137] Hellerhoff KJ, Helmberger H, 3rd, et al. Dynamic MR pancreatography after secretin administration: image quality and diagnostic accuracy. AJR Am J Roentgenol 2002;179:121-9.

[138] Manfredi R, Costamagna G, Brizi MG, et al. Severe chronic pancreatitis versus suspected pancreatic disease: dynamic MR cholangiopancreatography after secretin stimulation. Radiology 2000;214:849-55.

[139] Matos C, Cappeliez O, Winant C, et al. MR imaging of the pancreas: a pictorial tour. Radiographics 2002;22:e2.

[140] DiMagno MJ, Dimagno EP. Chronic pancreatitis. Curr Opin Gastroenterol 2006;22:487-97.

[141] Sugiyama M, Haradome H, Atomi Y. Magnetic resonance imaging for diagnosing chronic pancreatitis. J Gastroenterol 2007;42 Suppl 17:108-12.

[142] Akisik MF, Aisen AM, Sandrasegaran K, et al. Assessment of chronic pancreatitis: utility of diffusion-weighted MR imaging with secretin enhancement. Radiology 2009;250:103-9.

[143] Raimondo M, Wallace MB. Diagnosis of early chronic pancreatitis by endoscopic ultrasound. Are we there yet? JOP 2004;5:1-7.

[144] Gupta V, Toskes PP. Diagnosis and management of chronic pancreatitis. Postgrad Med J 2005;81:491-7.

[145] Draganov P, Toskes PP. Chronic pancreatitis. Curr Opin Gastroenterol 2002;18:558-62.

[146] Wallace MB, Hawes RH. Endoscopic ultrasound in the evaluation and treatment of chronic pancreatitis. Pancreas 2001;23:26-35.

[147] Catalano MF. Diagnosing early-stage chronic pancreatitis: is endoscopic ultrasound a reliable modality? J Gastroenterol 2007;42 Suppl 17:78-84.

[148] Forsmark CE. The diagnosis of chronic pancreatitis. Gastrointest Endosc 2000;52:293-8.

[149] Gleeson FC, Topazian M. Endoscopic retrograde cholangiopancreatography and endoscopic ultrasound for diagnosis of chronic pancreatitis. Curr Gastroenterol Rep 2007;9:123-9.

[150] Lankisch PG. The problem of diagnosing chronic pancreatitis. Dig Liver Dis 2003;35:131-4.

[151] Soto JA, Barish MA, Yucel EK, et al. Pancreatic duct: MR cholangiopancreatography with a three-dimensional fast spin-echo technique. Radiology 1995;196:459-64.

[152] Manfredi R, Costamagna G, Vecchioli A, et al. [Dynamic pancreatography with magnetic resonance after functional stimulus with secretin in chronic pancreatitis]. Radiol Med 1998;96:226-31.

[153] Nicaise N, Pellet $O$, Metens $T$, et al. Magnetic resonance cholangiopancreatography: interest of IV secretin administration in the evaluation of pancreatic ducts. Eur Radiol 1998;8:16-22.

[154] Bret PM, Reinhold C, Taourel P, et al. Pancreas divisum: evaluation with MR cholangiopancreatography. Radiology 1996;199:99-103.

[155] Delhaye M, Engelholm L, Cremer M. Pancreas divisum: congenital anatomic variant or anomaly? Contribution of endoscopic retrograde dorsal pancreatography. Gastroenterology 1985;89:951-8.

[156] Leyendecker JR, Elsayes KM, Gratz BI, et al. MR cholangiopancreatography: spectrum of pancreatic duct abnormalities. AJR Am J Roentgenol 2002;179:1465-71.

[157] Mortele KJ, Rocha TC, Streeter JL, et al. Multimodality imaging of pancreatic and biliary congenital anomalies. Radiographics 2006;26: $715-31$.

[158] Nijs E, Callahan MJ, Taylor GA. Disorders of the pediatric pancreas: imaging features. Pediatr Radiol 2005;35:358-73; quiz: 457.
[159] Reinhold C. Magnetic resonance imaging of the pancreas in 2001. J Gastrointest Surg 2002;6:133-5.

[160] Rosch W, Koch H, Schaffner O, et al. The clinical significance of the pancreas divisum. Gastrointest Endosc 1976;22:206-7.

[161] Akisik MF, Sandrasegaran K, Aisen AA, et al. Dynamic secretinenhanced MR cholangiopancreatography. Radiographics 2006;26: 665-77.

[162] Matos C, Bali MA, Delhaye M, et al. Magnetic resonance imaging in the detection of pancreatitis and pancreatic neoplasms. Best Pract Res Clin Gastroenterol 2006;20:157-78.

[163] Kim DH, Pickhardt PJ. Radiologic assessment of acute and chronic pancreatitis. Surg Clin North Am 2007;87:1341-58, viii.

[164] Memis A, Parildar M. Interventional radiological treatment in complications of pancreatitis. Eur J Radiol 2002;43:219-28.

[165] Kinney TP, Freeman ML. Recent advances and novel methods in pancreatic imaging. Minerva Gastroenterol Dietol 2008;54:85-95.

[166] Morris-Stiff G, Webster P, Frost B, et al. Endoscopic ultrasound reliably identifies chronic pancreatitis when other imaging modalities have been non-diagnostic. JOP 2009;10:280-3.

[167] Delhaye M, Arvanitakis M, Bali M, et al. Endoscopic therapy for chronic pancreatitis. Scand J Surg 2005;94:143-53.

[168] Deviere J, Bell RH, Jr., Beger HG, Traverso LW. Treatment of chronic pancreatitis with endotherapy or surgery: critical review of randomized control trials. J Gastrointest Surg 2008;12:640-4.

[169] Nealon WH, Thompson JC. Progressive loss of pancreatic function in chronic pancreatitis is delayed by main pancreatic duct decompression. A longitudinal prospective analysis of the modified puestow procedure. Ann Surg 1993;217:458-66; discussion: 466-8.

[170] Gabbrielli A, Pandolfi M, Mutignani M, et al. Efficacy of main pancreatic-duct endoscopic drainage in patients with chronic pancreatitis, continuous pain, and dilated duct. Gastrointest Endosc 2005;61:576-81.

[171] Dumonceau JM, Deviere J, Le Moine O, et al. Endoscopic pancreatic drainage in chronic pancreatitis associated with ductal stones: longterm results. Gastrointest Endosc 1996;43:547-55.

[172] Delhaye M, Arvanitakis M, Verset G, et al. Long-term clinical outcome after endoscopic pancreatic ductal drainage for patients with painful chronic pancreatitis. Clin Gastroenterol Hepatol 2004;2:1096-106.

[173] Brand B, Kahl M, Sidhu S, et al. Prospective evaluation of morphology, function, and quality of life after extracorporeal shockwave lithotripsy and endoscopic treatment of chronic calcific pancreatitis. Am J Gastroenterol 2000;95:3428-38.

[174] Dite P, Ruzicka M, Zboril V, et al. A prospective, randomized trial comparing endoscopic and surgical therapy for chronic pancreatitis. Endoscopy 2003;35:553-8.

[175] Cremer M, Deviere J, Delhaye M, et al. Stenting in severe chronic pancreatitis: results of medium-term follow-up in seventy-six patients. Endoscopy 1991;23:171-6.

[176] Ponchon T, Bory RM, Hedelius F, et al. Endoscopic stenting for pain relief in chronic pancreatitis: results of a standardized protocol. Gastrointest Endosc 1995;42:452-6.

[177] Ammann RW, Akovbiantz A, Largiader F, et al. Course and outcome of chronic pancreatitis. Longitudinal study of a mixed medical-surgical series of 245 patients. Gastroenterology 1984;86:820-8.

[178] Sherman S, Lehman GA, Hawes RH, et al. Pancreatic ductal stones: frequency of successful endoscopic removal and improvement in symptoms. Gastrointest Endosc 1991;37:511-7.

[179] Sauerbruch T, Holl J, Sackmann M, et al. Extracorporeal shock wave lithotripsy of pancreatic stones. Gut 1989;30:1406-11.

[180] den Toom R, Nijs HG, van Blankenstein M, et al. Extracorporeal shock wave treatment of common bile duct stones: experience with two different lithotriptors at a single institution. Br J Surg 1991;78: 809-13.

[181] Sauerbruch T, Holl J, Sackmann M, et al. Extracorporeal lithotripsy of pancreatic stones in patients with chronic pancreatitis and pain: a prospective follow up study. Gut 1992;33:969-72.

[182] van der Hul R, Plaisier P, Jeekel J, et al. Extracorporeal shock-wave lithotripsy of pancreatic duct stones: immediate and long-term results. Endoscopy 1994;26:573-8. 
[183] Delhaye M, Vandermeeren A, Baize M, et al. Extracorporeal shock-wave lithotripsy of pancreatic calculi. Gastroenterology 1992;102:610-20.

[184] Costamagna G, Gabbrielli A, Mutignani M, et al. Extracorporeal shock wave lithotripsy of pancreatic stones in chronic pancreatitis: immediate and medium-term results. Gastrointest Endosc 1997;46:231-6.

[185] Kozarek RA, Brandabur JJ, Ball TJ, et al. Clinical outcomes in patients who undergo extracorporeal shock wave lithotripsy for chronic calcific pancreatitis. Gastrointest Endosc 2002;56:496-500.

[186] Guda NM, Partington S, Freeman ML. Extracorporeal shock wave lithotripsy in the management of chronic calcific pancreatitis: a metaanalysis. JOP 2005;6:6-12.

[187] Inui K, Tazuma S, Yamaguchi T, et al. Treatment of pancreatic stones with extracorporeal shock wave lithotripsy: results of a multicenter survey. Pancreas 2005;30:26-30.

[188] Johanns W, Jakobeit C, Greiner L, et al. Ultrasound-guided extracorporeal shock wave lithotripsy of pancreatic ductal stones: six years' experience. Can J Gastroenterol 1996;10:471-5.

[189] Schreiber F, Gurakuqi GC, Pristautz H, et al. Sonographically-guided extracorporeal shockwave lithotripsy for pancreatic stones in patients with chronic pancreatitis. J Gastroenterol Hepatol 1996;11:247-51.

[190] Freeman ML. Mechanical lithotripsy of pancreatic duct stones. Gastrointest Endosc 1996;44:333-6.

[191] Schneider HT, May A, Benninger J, et al. Piezoelectric shock wave lithotripsy of pancreatic duct stones. Am J Gastroenterol 1994;89: 2042-8.

[192] Dumonceau JM, Costamagna G, Tringali A, et al. Treatment for painful calcified chronic pancreatitis: extracorporeal shock wave lithotripsy versus endoscopic treatment: a randomised controlled trial. Gut 2007; $56: 545-52$.

[193] Smits ME, Badiga SM, Rauws EA, et al. Long-term results of pancreatic stents in chronic pancreatitis. Gastrointest Endosc 1995;42:461-7.

[194] Binmoeller KF, Jue P, Seifert H, et al. Endoscopic pancreatic stent drainage in chronic pancreatitis and a dominant stricture: long-term results. Endoscopy 1995;27:638-44.

[195] Morgan DE, Smith JK, Hawkins K, et al. Endoscopic stent therapy in advanced chronic pancreatitis: relationships between ductal changes, clinical response, and stent patency. Am J Gastroenterol 2003;98: $821-6$.

[196] Eleftherladis N, Dinu F, Delhaye M, et al. Long-term outcome after pancreatic stenting in severe chronic pancreatitis. Endoscopy 2005;37: 223-30.

[197] Topazian M, Aslanian H, Andersen D. Outcome following endoscopic stenting of pancreatic duct strictures in chronic pancreatitis. J Clin Gastroenterol 2005;39:908-11.

[198] Costamagna G, Bulajic M, Tringali A, et al. Multiple stenting of refractory pancreatic duct strictures in severe chronic pancreatitis: longterm results. Endoscopy 2006;38:254-9.

[199] Weber A, Schneider J, Neu B, et al. Endoscopic stent therapy for patients with chronic pancreatitis: results from a prospective follow-up study. Pancreas 2007;34:287-94.

[200] Vitale GC, Cothron K, Vitale EA, et al. Role of pancreatic duct stenting in the treatment of chronic pancreatitis. Surg Endosc 2004;18:1431-4.

[201] Gregg JA, Carr-Locke DL, Gallagher MM. Importance of common bile duct stricture associated with chronic pancreatitis. Diagnosis by endoscopic retrograde cholangiopancreatography. Am J Surg 1981;141: 199-203.

[202] Kalvaria I, Bornman PC, Marks IN, et al. The spectrum and natural history of common bile duct stenosis in chronic alcohol-induced pancreatitis. Ann Surg 1989;210:608-13.

[203] Littenberg G, Afroudakis A, Kaplowitz N. Common bile duct stenosis from chronic pancreatitis: a clinical and pathologic spectrum. Medicine (Baltimore) 1979;58:385-412.

[204] Sarles H, Sahel J. Cholestasis and lesions of the biliary tract in chronic pancreatitis. Gut 1978;19:851-7.

[205] Eickhoff A, Jakobs R, Leonhardt A, et al. Endoscopic stenting for common bile duct stenoses in chronic pancreatitis: results and impact on long-term outcome. Eur J Gastroenterol Hepatol 2001;13:1161-7.
[206] Kahl S, Zimmermann S, Genz I, et al. Risk factors for failure of endoscopic stenting of biliary strictures in chronic pancreatitis: a prospective follow-up study. Am J Gastroenterol 2003;98:2448-53.

[207] Cahen DL, van Berkel AM, Oskam D, et al. Long-term results of endoscopic drainage of common bile duct strictures in chronic pancreatitis. Eur J Gastroenterol Hepatol 2005;17:103-8.

[208] Draganov P, Hoffman B, Marsh W, et al. Long-term outcome in patients with benign biliary strictures treated endoscopically with multiple stents. Gastrointest Endosc 2002;55:680-6.

[209] Catalano MF, Linder JD, George S, et al. Treatment of symptomatic distal common bile duct stenosis secondary to chronic pancreatitis: comparison of single vs. multiple simultaneous stents. Gastrointest Endosc 2004;60:945-52.

[210] Pozsar J, Sahin P, Laszlo F, et al. Medium-term results of endoscopic treatment of common bile duct strictures in chronic calcifying pancreatitis with increasing numbers of stents. J Clin Gastroenterol 2004;38:118-23.

[211] Dumonceau JM, Nicaise N, Deviere J. The ultraflex diamond stent for benign biliary obstruction. Gastrointest Endosc Clin N Am 1999;9: $541-5$.

[212] Cantu P, Hookey LC, Morales A, et al. The treatment of patients with symptomatic common bile duct stenosis secondary to chronic pancreatitis using partially covered metal stents: a pilot study. Endoscopy 2005;37:735-9.

[213] Yamaguchi T, Ishihara T, Seza K, et al. Long-term outcome of endoscopic metallic stenting for benign biliary stenosis associated with chronic pancreatitis. World J Gastroenterol 2006;12:426-30.

[214] Yeo CJ, Bastidas JA, Lynch-Nyhan A, et al. The natural history of pancreatic pseudocysts documented by computed tomography. Surg Gynecol Obstet 1990;170:411-7.

[215] Johnson MD, Walsh RM, Henderson JM, et al. Surgical versus nonsurgical management of pancreatic pseudocysts. J Clin Gastroenterol 2009;43:586-90.

[216] Melman L, Azar R, Beddow K, et al. Primary and overall success rates for clinical outcomes after laparoscopic, endoscopic, and open pancreatic cystgastrostomy for pancreatic pseudocysts. Surg Endosc 2009;23:267-71.

[217] Cahen D, Rauws E, Fockens P, et al. Endoscopic drainage of pancreatic pseudocysts: long-term outcome and procedural factors associated with safe and successful treatment. Endoscopy 2005;37:977-83.

[218] Giovannini M. What is the best endoscopic treatment for pancreatic pseudocysts? Gastrointest Endosc 2007;65:620-3.

[219] Hookey LC, Debroux S, Delhaye M, et al. Endoscopic drainage of pancreatic-fluid collections in 116 patients: a comparison of etiologies, drainage techniques, and outcomes. Gastrointest Endosc 2006;63:635-43.

[220] Sharma SS, Bhargawa N, Govil A. Endoscopic management of pancreatic pseudocyst: a long-term follow-up. Endoscopy 2002;34:203-7.

[221] Vignesh S, Brugge WR. Endoscopic diagnosis and treatment of pancreatic cysts. J Clin Gastroenterol 2008;42:493-506.

[222] Yusuf TE, Baron TH. Endoscopic transmural drainage of pancreatic pseudocysts: results of a national and an international survey of ASGE members. Gastrointest Endosc 2006;63:223-7.

[223] Varadarajulu S, Christein JD, Tamhane A, et al. Prospective randomized trial comparing EUS and EGD for transmural drainage of pancreatic pseudocysts (with videos). Gastrointest Endosc 2008;68:1102-11.

[224] Kahaleh M, Shami VM, Conaway MR, et al. Endoscopic ultrasound drainage of pancreatic pseudocyst: a prospective comparison with conventional endoscopic drainage. Endoscopy 2006;38:355-9.

[225] Lopes CV, Pesenti C, Bories E, et al. Endoscopic-ultrasoundguided endoscopic transmural drainage of pancreatic pseudocysts and abscesses. Scand J Gastroenterol 2007;42:524-9.

[226] D'Egidio A, Schein M. Pancreatic pseudocysts: a proposed classification and its management implications. $\mathrm{Br}$ J Surg 1991;78:981-4.

[227] Lankisch PG. Natural course of chronic pancreatitis. Pancreatology 2001;1:3-14. 
[228] Buchler MW, Friess H, Muller MW, et al. Randomized trial of duodenum-preserving pancreatic head resection versus pyloruspreserving Whipple in chronic pancreatitis. Am J Surg 1995;169:65-9; discussion: 69-70.

[229] Farkas G, Leindler L, Daroczi M, et al. Prospective randomised comparison of organ-preserving pancreatic head resection with pylorus-preserving pancreaticoduodenectomy. Langenbecks Arch Surg 2006;391:338-42.

[230] Izbicki JR, Bloechle C, Broering DC, et al. Extended drainage versus resection in surgery for chronic pancreatitis: a prospective randomized trial comparing the longitudinal pancreaticojejunostomy combined with local pancreatic head excision with the pyloruspreserving pancreatoduodenectomy. Ann Surg 1998;228:771-9.

[231] Izbicki JR, Bloechle C, Knoefel WT, et al. [Drainage versus resection in surgical therapy of chronic pancreatitis of the head of the pancreas: a randomized study]. Chirurg 1997;68:369-77.

[232] Klempa I, Spatny M, Menzel J, et al. [Pancreatic function and quality of life after resection of the head of the pancreas in chronic pancreatitis. A prospective, randomized comparative study after duodenum preserving resection of the head of the pancreas versus Whipple's operation]. Chirurg 1995;66:350-9.

[233] Koninger J, Seiler CM, Sauerland S, et al. Duodenum-preserving pancreatic head resection - a randomized controlled trial comparing the original Beger procedure with the Berne modification (ISRCTN No. 50638764). Surgery 2008;143:490-8.

[234] Sakorafas GH, Sarr MG. Pancreatic cancer after surgery for chronic pancreatitis. Dig Liver Dis 2003;35:482-5.

[235] van Gulik TM, Moojen TM, van Geenen R, et al. Differential diagnosis of focal pancreatitis and pancreatic cancer. Ann Oncol 1999;10 Suppl $4: 85-8$.

[236] Vijungco JD, Prinz RA. Management of biliary and duodenal complications of chronic pancreatitis. World J Surg 2003;27:1258-70.

[237] Rosso E, Alexakis N, Ghaneh P, et al. Pancreatic pseudocyst in chronic pancreatitis: endoscopic and surgical treatment. Dig Surg 2003;20:397406.

[238] Gouyon B, Levy P, Ruszniewski P, et al. Predictive factors in the outcome of pseudocysts complicating alcoholic chronic pancreatitis. Gut 1997;41:821-5.

[239] Vitas GJ, Sarr MG. Selected management of pancreatic pseudocysts: operative versus expectant management. Surgery 1992;111:123-30.

[240] D'Egidio A, Schein M. Percutaneous drainage of pancreatic pseudocysts: a prospective study. World J Surg 1992;16:141-5; discussion: 145-6.

[241] Heider R, Meyer AA, Galanko JA, et al. Percutaneous drainage of pancreatic pseudocysts is associated with a higher failure rate than surgical treatment in unselected patients. Ann Surg 1999;229:781-7; discussion: 787-9.

[242] Aghdassi A, Mayerle J, Kraft M, et al. Diagnosis and treatment of pancreatic pseudocysts in chronic pancreatitis. Pancreas 2008;36: 105-12.

[243] Nealon WH, Walser E. Surgical management of complications associated with percutaneous and/or endoscopic management of pseudocyst of the pancreas. Ann Surg 2005;241:948-57; discussion: 957-60.

[244] Ito K, Perez A, Ito H, et al. Pancreatic pseudocysts: is delayed surgical intervention associated with adverse outcomes? J Gastrointest Surg 2007;11:1317-21.

[245] Nealon WH, Walser E. Duct drainage alone is sufficient in the operative management of pancreatic pseudocyst in patients with chronic pancreatitis. Ann Surg 2003;237:614-20; discussion: 620-2.

[246] Agarwal AK, Raj Kumar K, Agarwal S, et al. Significance of splenic vein thrombosis in chronic pancreatitis. Am J Surg 2008;196:149-54.

[247] Heider TR, Azeem S, Galanko JA, et al. The natural history of pancreatitis-induced splenic vein thrombosis. Ann Surg 2004;239: 876-80; discussion: 880-2.

[248] Sakorafas GH, Sarr MG, Farley DR, et al. The significance of sinistral portal hypertension complicating chronic pancreatitis. Am J Surg 2000; 179:129-33.
[249] Nealon WH, Townsend CM, Jr., Thompson JC. Operative drainage of the pancreatic duct delays functional impairment in patients with chronic pancreatitis. A prospective analysis. Ann Surg 1988;208:321-9.

[250] Nealon WH, Walser E. Main pancreatic ductal anatomy can direct choice of modality for treating pancreatic pseudocysts (surgery versus percutaneous drainage). Ann Surg 2002;235:751-8.

[251] Lamme B, Boermeester MA, Straatsburg IH, et al. Early versus late surgical drainage for obstructive pancreatitis in an experimental model. Br J Surg 2007;94:849-54.

[252] Lankisch PG, Seidensticker F, Lohr-Happe A, et al. The course of pain is the same in alcohol- and nonalcohol-induced chronic pancreatitis. Pancreas 1995;10:338-41.

[253] Howard TJ, Jones JW, Sherman S, et al. Impact of pancreatic head resection on direct medical costs in patients with chronic pancreatitis. Ann Surg 2001;234:661-7.

[254] Edlund MJ, Steffick D, Hudson T, et al. Risk factors for clinically recognized opioid abuse and dependence among veterans using opioids for chronic non-cancer pain. Pain 2007;129:355-62.

[255] Abdallah AA, Krige JE, Bornman PC. Biliary tract obstruction in chronic pancreatitis. HPB (Oxford) 2007;9:421-8.

[256] Arslanlar S, Jain R. Benign biliary strictures related to chronic pancreatitis: balloons, stents, or surgery. Curr Treat Options Gastroenterol 2007;10:369-75.

[257] Bartoli E, Delcenserie R, Yzet T, et al. Endoscopic treatment of chronic pancreatitis. Gastroenterol Clin Biol 2005;29:515-21.

[258] Frey CF, Suzuki M, Isaji S. Treatment of chronic pancreatitis complicated by obstruction of the common bile duct or duodenum. World J Surg 1990;14:59-69.

[259] Sarr MG, Sakorafas GH. Incapacitating pain of chronic pancreatitis: a surgical perspective of what is known and what needs to be known. Gastrointest Endosc 1999;49:S85-9.

[260] van der Gaag NA, Gouma DJ, van Gulik TM, et al. Review article: Surgical management of chronic pancreatitis. Aliment Pharmacol Ther 2007;26 Suppl 2:221-32.

[261] Schnelldorfer T, Lewin DN, Adams DB. Reoperative surgery for chronic pancreatitis: is it safe? World J Surg 2006;30:1321-8.

[262] Hartel M, Tempia-Caliera AA, Wente MN, et al. Evidencebased surgery in chronic pancreatitis. Langenbecks Arch Surg 2003;388:132-9.

[263] Delcore R, Rodriguez FJ, Thomas JH, et al. The role of pancreatojejunostomy in patients without dilated pancreatic ducts. Am J Surg 1994;168:598-601; discussion: 601-2.

[264] Rios GA, Adams DB, Yeoh KG, et al. Outcome of lateral pancreaticojejunostomy in the management of chronic pancreatitis with nondilated pancreatic ducts. J Gastrointest Surg 1998;2:223-9.

[265] Jalleh RP, Aslam M, Williamson RC. Pancreatic tissue and ductal pressures in chronic pancreatitis. Br J Surg 1991;78:1235-7.

[266] Mihaljevic AL, Kleeff J, Friess H, et al. Surgical approaches to chronic pancreatitis. Best Pract Res Clin Gastroenterol 2008;22:167-81.

[267] Partington PF, Rochelle RE. Modified Puestow procedure for retrograde drainage of the pancreatic duct. Ann Surg 1960;152:1037-43.

[268] Zollinger RM. Pancreatitis. Postgrad Med 1954;15:323-33.

[269] Duval MK, Jr. Caudal pancreatico-jejunostomy for chronic relapsing pancreatitis. Ann Surg 1954;140:775-85.

[270] Puestow CB, Gillesby WJ. Retrograde surgical drainage of pancreas for chronic relapsing pancreatitis. AMA Arch Surg 1958;76:898-907.

[271] Adams DB, Ford MC, Anderson MC. Outcome after lateral pancreaticojejunostomy for chronic pancreatitis. Ann Surg 1994;219: 481-7; discussion: 487-9.

[272] Greenlee HB, Prinz RA, Aranha GV. Long-term results of side-to-side pancreaticojejunostomy. World J Surg 1990;14:70-6.

[273] Markowitz JS, Rattner DW, Warshaw AL. Failure of symptomatic relief after pancreaticojejunal decompression for chronic pancreatitis. Strategies for salvage. Arch Surg 1994;129:374-9; discussion: 379-80.

[274] Prinz RA, Aranha GV, Greenlee HB. Redrainage of the pancreatic duct in chronic pancreatitis. Am J Surg 1986;151:150-6. 
[275] Sakorafas GH, Zobolas B. Lateral pancreatojejunostomy in the surgical management of chronic pancreatitis. Current concepts and future perspectives. Dig Liver Dis 2001;33:187-91.

[276] Andersson R, Borjesson A, Blind PJ, et al. Pancreaticojejunostomy: a valid operation in chronic pancreatitis? Scand J Gastroenterol 2008; 43:1000-3.

[277] Lucas CE, McIntosh B, Paley D, et al. Surgical decompression of ductal obstruction in patients with chronic pancreatitis. Surgery 1999; 126:790-5; discussion: 795-7.

[278] Prinz RA, Greenlee HB. Pancreatic duct drainage in 100 patients with chronic pancreatitis. Ann Surg 1981;194:313-20.

[279] Beger HG, Krautzberger W, Bittner R, et al. Duodenum-preserving resection of the head of the pancreas in patients with severe chronic pancreatitis. Surgery 1985;97:467-73.

[280] Frey CF, Smith GJ. Description and rationale of a new operation for chronic pancreatitis. Pancreas 1987;2:701-7.

[281] Gloor B, Friess H, Uhl W, et al. A modified technique of the Beger and Frey procedure in patients with chronic pancreatitis. Dig Surg 2001;18:21-5.

[282] Izbicki JR, Bloechle C, Broering DC, et al. Longitudinal V-shaped excision of the ventral pancreas for small duct disease in severe chronic pancreatitis: prospective evaluation of a new surgical procedure. Ann Surg 1998;227:213-9.

[283] Diener MK, Rahbari NN, Fischer L, et al. Duodenum-preserving pancreatic head resection versus pancreatoduodenectomy for surgical treatment of chronic pancreatitis: a systematic review and metaanalysis. Ann Surg 2008;247:950-61.

[284] Izbicki JR, Bloechle C, Knoefel WT, et al. Duodenum-preserving resection of the head of the pancreas in chronic pancreatitis. A prospective, randomized trial. Ann Surg 1995;221:350-8.

[285] Strate T, Taherpour Z, Bloechle C, et al. Long-term follow-up of a randomized trial comparing the beger and frey procedures for patients suffering from chronic pancreatitis. Ann Surg 2005;241:591-8.

[286] Ho HS, Frey CF. The Frey procedure: local resection of pancreatic head combined with lateral pancreaticojejunostomy. Arch Surg 2001; 136:1353-8.

[287] Yekebas EF, Bogoevski D, Honarpisheh H, et al. Long-term follow-up in small duct chronic pancreatitis: A plea for extended drainage by "V-shaped excision" of the anterior aspect of the pancreas. Ann Surg 2006;244:940-6; discussion: 946-8.

[288] Jimenez RE, Fernandez-del Castillo C, Rattner DW, et al. Outcome of pancreaticoduodenectomy with pylorus preservation or with antrectomy in the treatment of chronic pancreatitis. Ann Surg 2000;231:293-300.

[289] Jimenez RE, Fernandez-Del Castillo C, Rattner DW, et al. Pyloruspreserving pancreaticoduodenectomy in the treatment of chronic pancreatitis. World J Surg 2003;27:1211-6.

[290] Sakorafas GH, Farnell MB, Nagorney DM, et al. Pancreatoduodenectomy for chronic pancreatitis: long-term results in 105 patients. Arch Surg 2000;135:517-23; discussion: 523-4.

[291] Schnelldorfer T, Lewin DN, Adams DB. Operative management of chronic pancreatitis: longterm results in 372 patients. J Am Coll Surg 2007;204:1039-45; discussion: 1045-7.

[292] Jovanovic I, Alempijevic T, Lukic S, et al. Cystic dystrophy in heterotopic pancreas of the duodenal wall. Dig Surg 2008;25:262-8.

[293] Witzigmann H, Max D, Uhlmann D, et al. Outcome after duodenumpreserving pancreatic head resection is improved compared with classic Whipple procedure in the treatment of chronic pancreatitis. Surgery 2003;134:53-62.

[294] Belina F, Fronek J, Ryska M. Duodenopancreatectomy versus duodenum-preserving pancreatic head excision for chronic pancreatitis. Pancreatology 2005;5:547-52.

[295] Muller MW, Friess H, Martin DJ, et al. Long-term follow-up of a randomized clinical trial comparing Beger with pylorus-preserving Whipple procedure for chronic pancreatitis. Br J Surg 2008;95:350-6.

[296] Chiang KC, Yeh CN, Hsu JT, et al. Pancreaticoduodenectomy versus Frey's procedure for chronic pancreatitis: preliminary data on outcome and pancreatic function. Surg Today 2007;37:961-6.

[297] Varghese TK, Bell RH, Jr. Duodenum-preserving head resection for chronic pancreatitis: an institutional experience and national survey of usage. Surgery 2007;142:588-93; discussion: 593 e1-3.

[298] Hutchins RR, Hart RS, Pacifico M, et al. Long-term results of distal pancreatectomy for chronic pancreatitis in 90 patients. Ann Surg 2002; 236:612-8.

[299] Kleeff J, Diener MK, Z'Graggen K, et al. Distal pancreatectomy: risk factors for surgical failure in 302 consecutive cases. Ann Surg 2007;245:573-82.

[300] Sakorafas GH, Sarr MG, Rowland CM, et al. Postobstructive chronic pancreatitis: results with distal resection. Arch Surg 2001;136:643-8.

[301] Rattner DW, Fernandez-del Castillo C, Warshaw AL. Pitfalls of distal pancreatectomy for relief of pain in chronic pancreatitis. Am J Surg 1996;171:142-5; discussion 145-6.

[302] Schoenberg MH, Schlosser W, Ruck W, et al. Distal pancreatectomy in chronic pancreatitis. Dig Surg 1999;16:130-6.

[303] Sawyer R, Frey CF. Is there still a role for distal pancreatectomy in surgery for chronic pancreatitis? Am J Surg 1994;168:6-9.

[304] Alexakis N, Ghaneh P, Connor S, et al. Duodenum- and spleenpreserving total pancreatectomy for end-stage chronic pancreatitis. $\mathrm{Br}$ J Surg 2003;90:1401-8.

[305] Blondet JJ, Carlson AM, Kobayashi T, et al. The role of total pancreatectomy and islet autotransplantation for chronic pancreatitis. Surg Clin North Am 2007;87:1477-501, x.

[306] Muller MW, Friess H, Kleeff J, et al. Is there still a role for total pancreatectomy? Ann Surg 2007;246:966-74; discussion: 974-5.

[307] Argo JL, Contreras JL, Wesley MM, et al. Pancreatic resection with islet cell autotransplant for the treatment of severe chronic pancreatitis. Am Surg 2008;74:530-6; discussion: 536-7.

[308] Garcea G, Weaver J, Phillips J, et al. Total pancreatectomy with and without islet cell transplantation for chronic pancreatitis: a series of 85 consecutive patients. Pancreas 2009;38:1-7.

[309] Heidt DG, Burant C, Simeone DM. Total pancreatectomy: indications, operative technique, and postoperative sequelae. J Gastrointest Surg 2007;11:209-16.

[310] Zamboni G, Capelli P, Scarpa A, et al. Nonneoplastic mimickers of pancreatic neoplasms. Arch Pathol Lab Med 2009;133:439-53.

[311] Kloppel G, Adsay NV. Chronic pancreatitis and the differential diagnosis versus pancreatic cancer. Arch Pathol Lab Med 2009;133:382-7.

[312] Sharma S, Green KB. The pancreatic duct and its arteriovenous relationship: an underutilized aid in the diagnosis and distinction of pancreatic adenocarcinoma from pancreatic intraepithelial neoplasia. A study of 126 pancreatectomy specimens. Am J Surg Pathol 2004;28:613-20.

[313] Bandyopadhyay S, Basturk O, Coban I, et al. Isolated solitary ducts (naked ducts) in adipose tissue: a specific but underappreciated finding of pancreatic adenocarcinoma and one of the potential reasons of understaging and high recurrence rate. Am J Surg Pathol 2009;33: $425-9$.

[314] Tanaka M, Chari S, Adsay V, et al. International consensus guidelines for management of intraductal papillary mucinous neoplasms and mucinous cystic neoplasms of the pancreas. Pancreatology 2006;6:17-32.

[315] Hruban RH, Takaori K, Klimstra DS, et al. An illustrated consensus on the classification of pancreatic intraepithelial neoplasia and intraductal papillary mucinous neoplasms. Am J Surg Pathol 2004;28:977-87. 